\title{
On the Role of Power Electronics in Visible Light Communication
}

\author{
Javier Sebastián, Senior Member, IEEE, Diego G. Lamar, Member, IEEE, Daniel G. Aller, Student \\ Member, IEEE, Juan Rodríguez, Student Member, IEEE, and Pablo F. Miaja, Member, IEEE.
}

\begin{abstract}
The continuous demand of increasing data rates provided by wireless communication systems is contributing to saturating the RF spectrum. Visible Light Communication (VLC) systems aim to alleviate this congestion by using the visible light spectrum. These systems have been proposed to make use of High-Brightness LEDs (HB-LEDs) not only for lighting, but also for transmitting information by rapidly changing the intensity of the emitted light. A critical issue is that VLC requires a fast HB-LED driver in order to reproduce the target light intensity waveforms, which can include components of several MHz. Consequently, the HB-LED drivers proposed to date are based on the use of an RF Power Amplifier (RFPA). These devices provide the required speed, but suffer from very high power losses. To overcome this drawback, different solutions based on the use of fastresponse DC/DC converters are presented in this paper. Several DC/DC converters, either to be used instead of an RFPA or to help an RFPA to achieve high efficiency, are thus analysed. The proposed HB-LED drivers enable the implementation of VLC transmitters without sacrificing one of the most important advantages of HB-LED lighting, namely its high power efficiency.
\end{abstract}

Index Terms-Visible Light Communication (VLC), High-Brightness LEDs (HB-LEDs) and Fast-response DC/DC converters.

\section{INTRODUCTION}

Broad bandwidth wireless communication systems are widely used nowadays. These systems tend to increase the bit rate in order to enable different services, including cellular communications and internet access via $3 \mathrm{G}$ and $4 \mathrm{G}$, WiFi networking, digital video broadcasting for terrestrial television, and small area networks using Bluetooth and ZigBee, among others. All these services make use of the RF spectrum to perform their transmission capabilities. Access to the RF spectrum is strictly regulated in order to accommodate such an extensive number of services, allowing all of them to operate without interfering with each other or with other systems such as RADAR, radio telescopes, and so on. In addition, each service tends to demand greater bandwidth in order to increase its quality. This has converted the RF spectrum into a scarce resource [1, 2] and several attempts have been made to allow fair resource allocation, even using new techniques such as cognitive radio. Furthermore, there are certain environments in which the use of the RF spectrum is prohibited or unsuitable due to the problems caused by interference with critical systems (aviation, hospitals, nuclear power plants, etc.). Consequently, alternative wireless communication systems, like Optical Wireless Communication (OWC), have been explored over the last few decades.

Standards have recently been proposed for Visible Light Communication (VLC) [3, 4], a subcategory of OWC. VLC is a wireless communication system that combines the transmission task with the illumination functionality of Solid-State Lighting (SSL) systems. VLC standards propose the use of visible light to provide both communications and lighting tasks. VLC modulates the light intensity emitted by High-Brightness LEDs (HB-LEDs), instead of modulating the amplitude and/or frequency and/or phase of an RF signal, as occurs in standard communications. It should be noted that the frequency of the light intensity variations has to be high enough so as not to impinge on the illumination task. In order to modulate the emitted light intensity, the current through the HB-LEDs has to be carefully controlled. Current modulation is thus translated into light intensity modulation following the characteristics of HB-LEDs. Moreover, as both the illumination and communication functionalities have to be provided by the same HB-LED (or string of HB-LEDs), the modulated current should be situated around a DC bias level. This DC current bias will perform the illumination task, while the information will be provided by the current variations in the vicinity of this DC current bias. The following are some of the main benefits of VLC :

- VLC opens up a large license-free visible region for wireless communication in comparison to the restricted and expensive RF spectrum.

- No special facilities are needed to implement VLC systems, because, in principle, they can be integrated into preexisting lighting systems.

- As visible light cannot penetrate building walls, VLC provides communication security and naturally avoids interference with other VLC systems from adjacent rooms, thus providing the entire available bandwidth for each closed environment.

- VLC is especially attractive in the following cases:

a) Internet connectivity in indoor scenarios, where the existing lighting infrastructure can be adapted. 
b) Vehicle to vehicle communications, where VLC can be implemented using cars headlights.

c) Underwater communications, where light is less attenuated than RF signals.

d) Wireless communications in scenarios where $\mathrm{RF}$ communication is dangerous, such as airplanes, mines and hospitals.

The information can be sent by the HB-LED employing different strategies. To illustrate this, a baseband digital signal, $\mathrm{s}_{1}$, will be considered (see Fig. 1a). The possibilities for sending this signal are the following:

a) First, an AC current, $i_{a c \_L E D}$, is added to a bias current, $\mathrm{i}_{\text {bias_LED }}$ (see Fig. 1b), thus preforming the total current passing through the HB-LED, $\mathrm{i}_{\mathrm{LED}}$. The AC current, $\mathrm{i}_{\text {ac_LED, }}$ is a square waveform that can be either proportional to the baseband signal, $\mathrm{s}_{1}$ (as shown in Fig. 1b), or a type of pulse modulation of this signal [5-8]. From the telecommunication theory perspective, white light plays the role of a multicarrier RF signal of extremely high frequency (above the terahertz range), whose intensity is modulated with the baseband information. From a more practical perspective, we will consider the amplitude of white light to be directly modulated with pulses that contain the baseband information. We will call this scheme Pulse-Based Transmission (PBT). Fig. 1c shows a diagram of a very simple VLC transmitter for PBT with the same structure

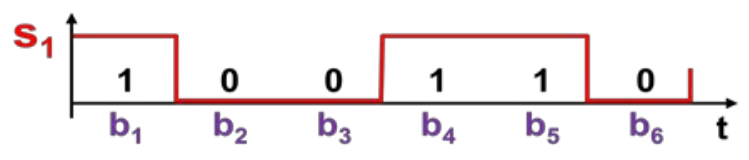

a)

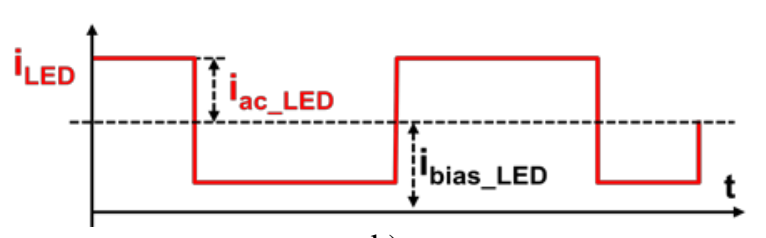

b)

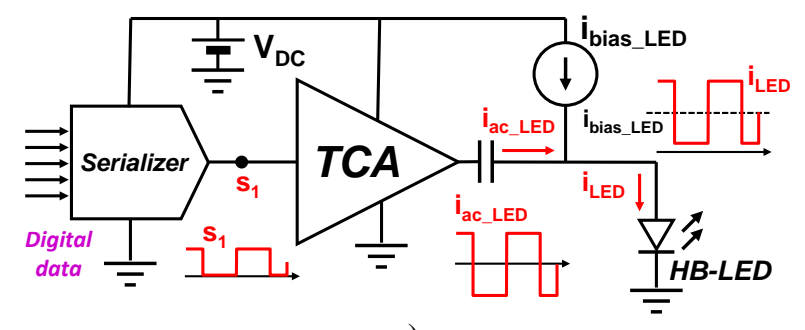

c)

Fig. 1. Pulse-Based Transmission. a) Signal to be transmitted. b) Current passing through the HB-LED. c) Transmitter scheme. as a transmitter for Fiber-Optic Communication (FOC) [9]. The digital information is serialized and translated to the appropriate current levels via a Transconductance Amplifier (TCA). At the output, a constant current source, $\mathrm{i}_{\text {bias_LED, }}$ is added to bias the HB-LED. This scheme is very simple, but the communication is affected by many other possible focuses of light, which is a problem that exists in VLC, but not in FOC. Moreover, this scheme does not avoid the issues arising from the different trajectories that the light rays can follow from the light focus to the receiver (i.e., the multipath issue) and it cannot achieve bit rates as high as those obtained using the communication strategies explained below.

b) The second possibility is to modulate the white light with a carrier $\mathrm{v}_{\mathrm{c}}$, which is also modulated with signal $\mathrm{s}_{1}$. Once again from the telecommunication theory perspective, an extremely high-frequency multicarrier RF signal (white light) is modulated in Amplitude Modulation (AM) with a subcarrier in the megahertz range. This subcarrier is modulated with the baseband information using conventional modulation schemes suitable for sending digital information [10,11], such as Amplitude-Shift Keying (ASK), Frequency-Shift Keying (FSK), Phase-Shift Keying (PSK), Quadrature Amplitude Modulation (QAM), or similar. According to a more practical perspective (as mentioned previously), we will consider the light intensity to now be modulated with a carrier, which is in turn digitally modulated. As an example, Fig. 2a shows the HB-LED current when the light intensity has been modulated with a sinusoidal signal, which is in turn modulated with the simplest digital modulation, namely ASK. The modulated signal is amplified using an RF Power Amplified (RFPA), which must be able to operate at the frequency of the aforementioned sinusoidal signal. The AC signal thus

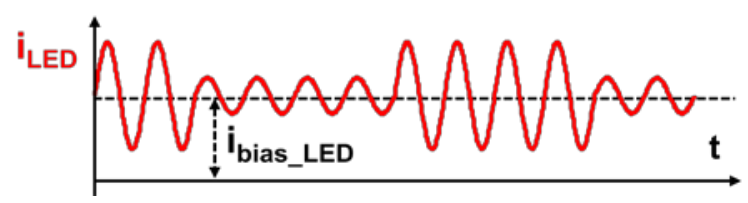

a)

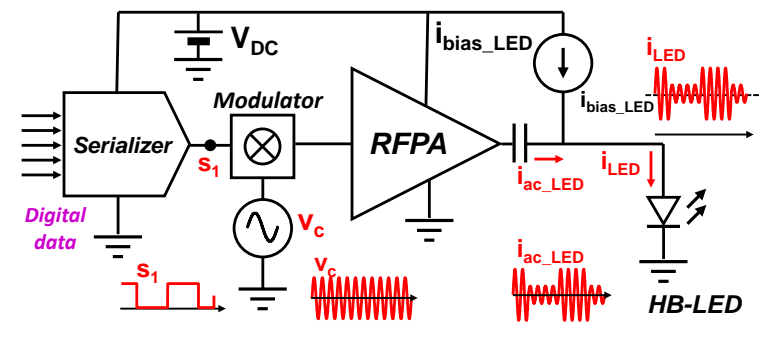

b)

Fig. 2. Single-Carrier Modulated Transmission. a) Current passing through the HB-LED. b) Transmitter scheme. 
obtained is added to the HB-LED bias current, $\mathrm{i}_{\text {bias_LED, }}$ to provide the total HB-LED current, $i_{\text {LED }}$. In this case, immunity to interference from other focuses of light increases and more than one transmission can occur in the same room if carriers of different frequencies are used. We will call this kind of modulation scheme Single-Carrier Modulated Transmission (SCMT). In spite of the aforementioned advantages, this scheme does not overcome the multipath issue.

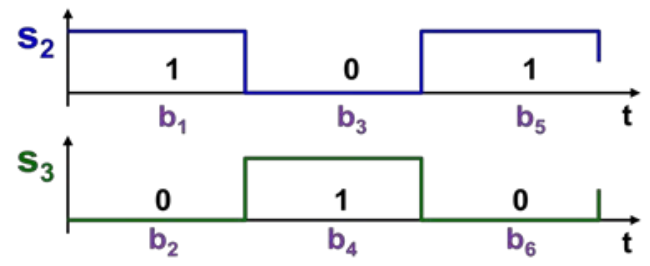

a)

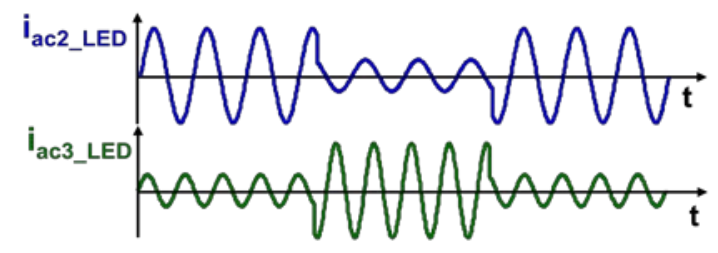

b)

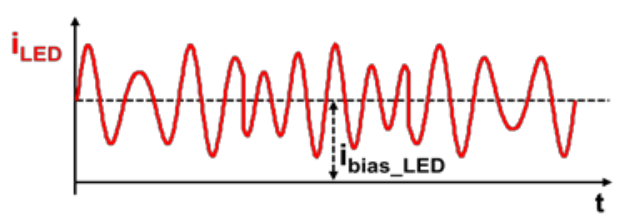

c)

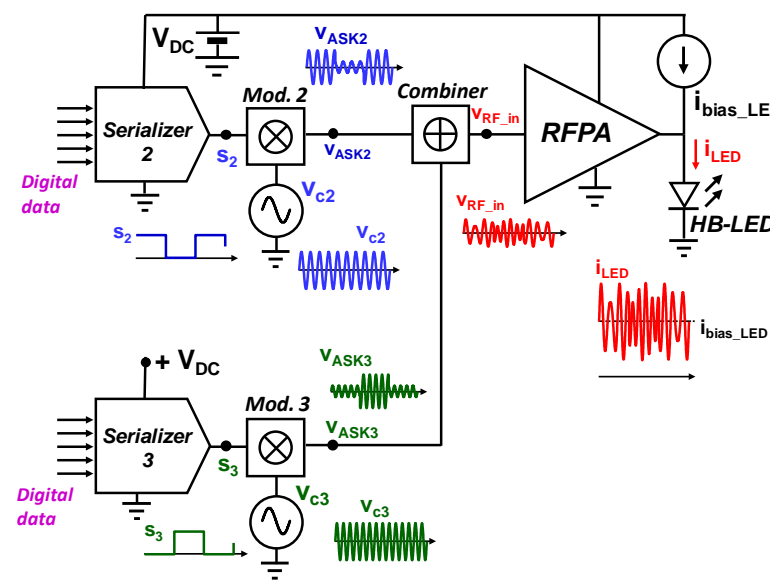

d)

Fig. 3. Multiple-Carrier Modulated Transmission. a) Sequences of bits to be transmitted. b) Signals modulated with signals $\mathrm{s}_{2}$ and $\mathrm{s}_{3}$. c) Current passing through the HB-LED. d) Transmitter scheme based on a single broadband RFPA.

c) The third possibility is to split the digital information into several sequences of bits (instead of one) and to modulate several carriers with these sequences [7, 12-22]. Also as an example, Fig. 3a shows two sequences of bits, $s_{2}$ (odd bits of $s_{1}: b_{1}, b_{3}$ and $b_{5}$ ) and $s_{3}$ (even bits of $s_{1}: b_{2}, b_{4}$ and $b_{6}$ ), with the same information as $s_{1}$, but with a slower bit rate. These signals are used to modulate carriers $\mathrm{v}_{\mathrm{c} 2}$ and $\mathrm{v}_{\mathrm{c} 3}$ (of different frequencies, see Fig. 3b) using ASK, thus obtaining signals $\mathrm{v}_{\mathrm{ASK} 2}$ and $\mathrm{v}_{\mathrm{ASK} 3}$. Once we have two modulated signals, we have three possibilities:

- To add both signals using a combiner and amplify the signal thus obtained using a single broadband RFPA (see Fig. 3d).

- To amplify both signals using different narrow-band RFPAs and to add the resulting signals before delivering them to the HB-LED (see Fig. 4a).

- To amplify both signals using different narrowband RFPAs and deliver the amplified signals to two different HB-LEDs (see Fig. 4b).

In all these cases, the appropriate bias current, $i_{\text {bias_LED, }}$ must be delivered to the HB-LED. Obviously, the process
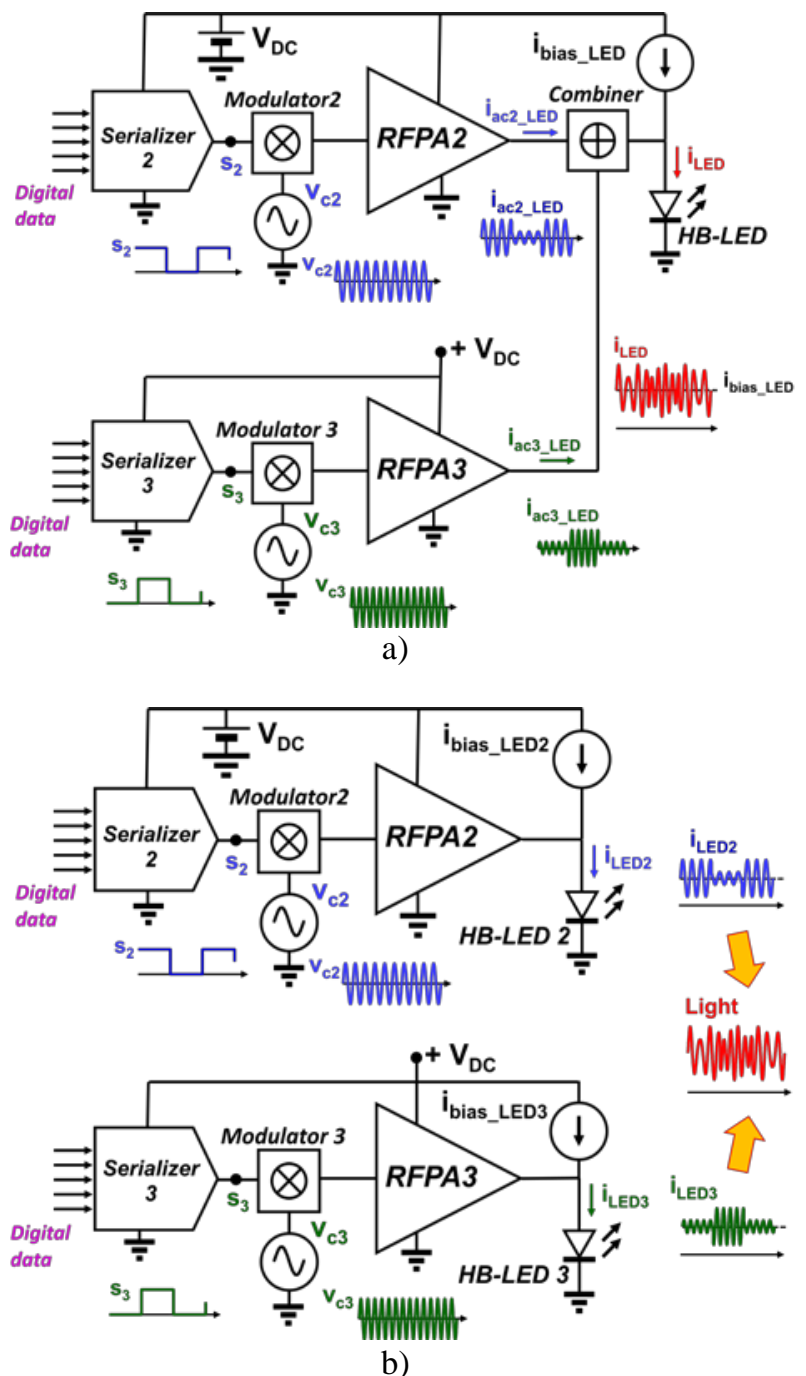

Fig. 4. Multiple-Carrier Modulated Transmission with several RF Power Amplifiers. a) With only one HB-LED. b) With one HB-LED per RFPA. 
described here for two carriers can be generalized to several carriers, signals and types of modulation. Moreover, a combination of the structures depicted in Figs. $4 \mathrm{a}$ and $4 \mathrm{~b}$ can be adopted when many carriers are used. We will call this scheme Multiple-Carrier Modulated Transmission (MCMT). The main advantage of using MCMT is that the multipath issue is mitigated.

Most of the existing literature focuses on the signal processing involved, modulations used and their implementations [5-22], the modelling of LEDs [20] and some low-power, custom-made hardware for emitters and receivers $[9,23-25]$. The bit rate provided by VLC systems is continuously increasing [26-33] thanks to the use of complex modulation and/or multiplexing schemes such as QAM [34], Wavelength Division Multiplexing (WDM) [32] and Orthogonal Frequency Division Multiplexing (OFDM) [7, 1222]. These schemes increase spectral efficiency (which means that higher bit rates can be achieved) and mitigate other problems, like the multipath issue. However, the solutions presented in the aforementioned papers avoid a key aspect: the poor power efficiency achieved in the transmitters. Hence, their power levels are quite low; notably lower than those needed in real lighting applications. This is because the RFPAs are operating in Class A, Class B or Class AB to achieve the broad bandwidth and linearity demanded by these complex modulation/multiplexing schemes. The efficiency of these RFPAs may be as low as $10 \%$, thus penalizing the efficiency of the overall transmitter.

In order to increase the power levels associated with the light emitted and, at the same time, achieve high power efficiency, solutions derived from switching-mode DC/DC converters should be explored. The main objective of this paper is thus to establish a "road map" addressing the possible contribution of power electronics technology to the practical development of visible light communication. The use of one or several DC/DC converters can contribute to overcoming the efficiency issue because they can either perform both the DC biasing and the light intensity modulation (i.e., the illumination and transmission functionalities) or contribute to increasing the efficiency of the overall system by increasing the efficiency of the RFPAs.

Some implementations of DC/DC converters performing both illumination and transmission functionalities have already been proposed [35-38]. However, as stated in [39], the bit rate achieved is too low due to the simple modulation schemes used: On-Off Keying (OOK) or Pulse Position Modulation (PPM), which correspond to the case of PBT. In order to overcome this limitation, a set of possible implementations of high efficiency VLC transmitters based on the use of DC/DC converters will be addressed in the next section. These converters will be responsible for increasing the bit rate by allowing the use of the aforementioned complex modulation/multiplexing schemes while maintaining high-power efficiency in the transmitter.

\section{USING SWITCHING-MODE DC/DC CONVERTERS TO INCREASE THE EFFICIENCY OF VLC TRANSMITTERS}

As in the case of any electronic device, a switching-mode converter (either $\mathrm{AC} / \mathrm{DC}$ or $\mathrm{DC} / \mathrm{DC}$ ) will be responsible for generating the DC voltage level needed to supply power to each piece of VLC equipment. The voltage source represented as $V_{D C}$ in the circuits shown in Figs. 1-4 will be the output port of this converter. No specific design constraints will distinguish this first converter from any other converter.

In addition to the aforementioned converter, other power converters (in this case, DC/DC converters) can help increase the efficiency of VLC transmitters. These will be described in the following sub-sections.

\section{A. Slow-response DC/DC converters used to generate the bias current for strings of HB-LEDs}

A DC/DC converter can be used to generate the DC level of the current passing through the HB-LEDs (see Fig. 5). An RF

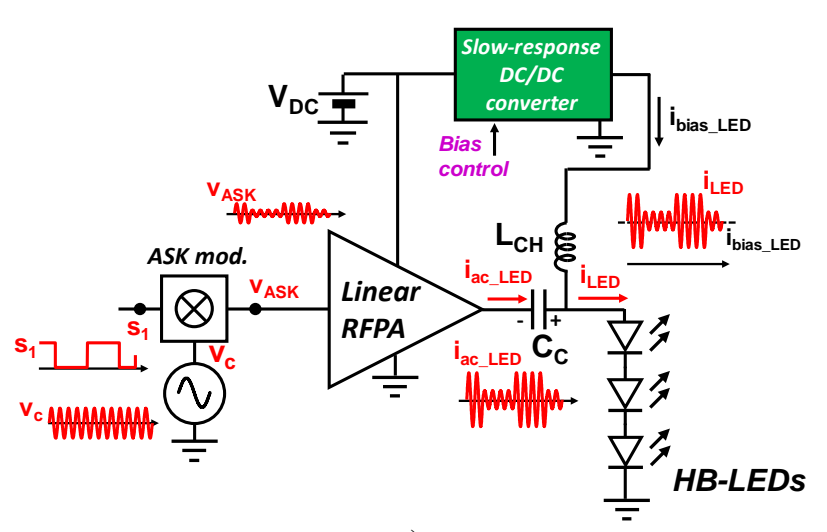

a)

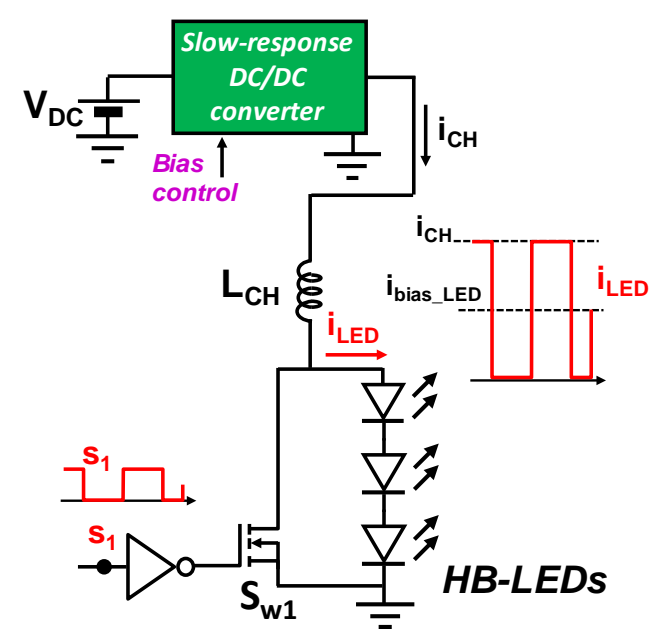

b)

Fig. 5. Slow-response DC/DC converter used to generate the bias current of an HB-LED string used for VLC. a) Example of an SCMT with ASK modulation. b) Example of a PBT using a switching transistor, $\mathrm{S}_{\mathrm{W} 1}$. 
choke inductor, $\mathrm{L}_{\mathrm{CH}}$, blocks the flow of the AC current from the RFPA to the DC/DC converter, while the coupling capacitor, $\mathrm{C}_{\mathrm{C}}$, allows the AC current to flow from the RFPA to the string of HB-LEDs. The DC/DC converter may be a standard HB-LED driver, which means that it is a slow-response converter, whose design does not pose a significant challenge. The information will be amplified by either an RFPA (as shown in Fig. 5) or a power TCA (in the case of PBT). In the latter case, however, special arrangements can be used, an example of which is shown in Fig. 5b. In this example, the slow-response DC/DC is responsible for generating the choke inductor current, $\mathrm{i}_{\mathrm{CH}}$, as in the case of the circuit given in Fig. 5a, but this current is now the peak value of the current passing through the HB-LED string, instead of being its bias value.

\section{B. Fast-response DC/DC converters used to synthesize the whole current passing through the HB-LED string: Direct Synthesis}

In this case, also only a DC/DC converter is used in the final implementation. However, this converter is very challenging in this case, because it is responsible for generating both the DC bias current and the AC current level corresponding to the information to be transmitted, for PBT (see Fig. 6a), SCMT (see Fig. 6b), or MCMT. The cut-off frequency corresponding to the transfer function between the control variable (the converter duty cycle) and the output voltage must be higher than the highest frequency component of the AC current passing through the HB-LED string. In practice, this means that extremely fast response converters must be used for this purpose. We will call this type of operation Direct Synthesis (DS).

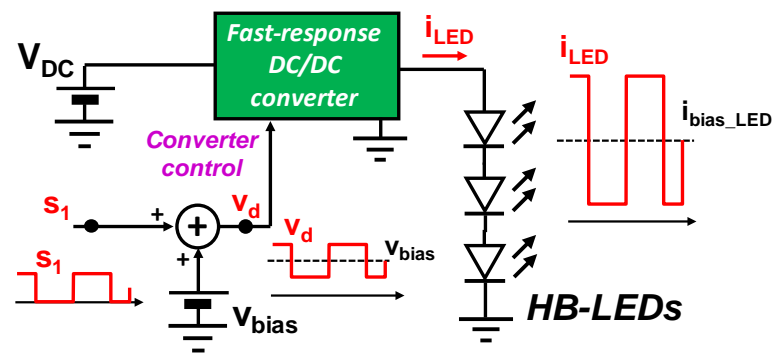

a)

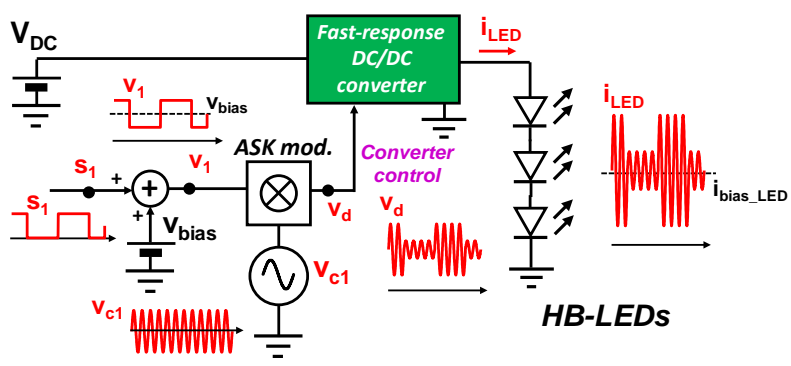

b)

Fig. 6. Fast-response DC/DC converters used to synthesize the current passing through an HB-LED string for VLCs. a) Synthesis of a PBT. b) Synthesis of an SCMT with ASK modulation.
Over the last decade, fast-response DC/DC converters capable of changing their output voltage at $\mathrm{MHz}$ rate have been proposed to implement techniques used to increase the efficiency of RFPAs. The most popular of these techniques are Envelope Tracking (ET) and Envelope Elimination and Restoration (EER) [40]. In both cases, a fast-response DC/DC converter has to generate the time-varying output voltage that is used as the power supply for the RFPA. The variations in this voltage are imposed by the envelope of the communication signal processed by the RFPA. This fast-response DC/DC converter is often known as an Envelope Modulator or Envelope Amplifier. Over the years, several designs have been proposed for fast-response DC/DC converters conceived to work as Envelope Amplifiers [41-50]. Most of these designs derive from the Buck converter, as this converter exhibits linearity between the control and the output voltage if it has been designed to operate in Continuous Conduction Mode (CCM). Some examples of these converters are shown in Fig. 7. In the case of the converter shown in Fig. 7a, the output voltage, $v_{0}$, is controlled by duty cycles $d_{1}, d_{2}$ and $d_{3}$ (corresponding to transistors $S_{1}, S_{2}$ and $S_{3}$, respectively) according to the following equations:

$$
\begin{aligned}
& \text { - If } 0<\mathrm{v}_{\mathrm{o}}<\mathrm{V}_{\mathrm{DC} 1} \text {, then } \mathrm{d}_{2}=\mathrm{d}_{3}=0, \mathrm{v}_{\mathrm{o}}=\mathrm{d}_{1} \cdot \mathrm{V}_{\mathrm{DC} 1} \text {. } \\
& \text { - If } \mathrm{V}_{\mathrm{DC} 1}<\mathrm{V}_{\mathrm{o}}<\mathrm{V}_{\mathrm{DC} 2} \text {, then } \mathrm{d}_{1}=1, \mathrm{~d}_{3}=0, \mathrm{v}_{\mathrm{o}}=\mathrm{d}_{2} \cdot\left(\mathrm{V}_{\mathrm{DC} 2}-\mathrm{V}_{\mathrm{DC} 1}\right) \\
& +\mathrm{V}_{\mathrm{DC} 1} . \\
& \text { - If } \mathrm{V}_{\mathrm{DC} 2}<\mathrm{V}_{\mathrm{o}}<\mathrm{V}_{\mathrm{DC} 3} \text {, then } \mathrm{d}_{1}=0, \mathrm{~d}_{2}=1, \mathrm{v}_{\mathrm{o}}=\mathrm{d}_{3} \cdot\left(\mathrm{V}_{\mathrm{DC} 3}-\mathrm{V}_{\mathrm{DC} 2}\right) \\
& \quad+\mathrm{V}_{\mathrm{DC} 2} .
\end{aligned}
$$

In the case of the converter shown in Fig. 7b, both transistors operate with the same duty cycle, $d$ (however, the control signals are $180^{\circ}$ out of phase). The output voltage, $\mathrm{v}_{\mathrm{o}}$, is determined by $\mathrm{d}$ as in any conventional buck converter:

$$
\mathrm{V}_{\mathrm{o}}=\mathrm{d} \cdot \mathrm{V}_{\mathrm{DC}} \text {. }
$$

In the case of the converter shown in Fig. 7c, the output voltage, $v_{0}$, is controlled by duty cycles $d_{1}, d_{2}, d_{3}$ and $d_{4}$ (corresponding to transistors $\mathrm{S}_{1}, \mathrm{~S}_{2}, \mathrm{~S}_{3}$, and $\mathrm{S}_{4}$, respectively) and by the duty cycle, $d$, of the two-phase buck converter (its control signals are $180^{\circ}$ out of phase), according to the following equations:

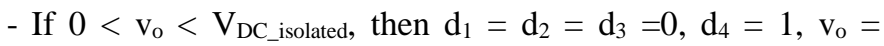
$\mathrm{d} \cdot \mathrm{V}_{\mathrm{DC} \text { _isolated. }}$

- If $\mathrm{V}_{\mathrm{DC} 1}<\mathrm{v}_{\mathrm{o}}<\mathrm{V}_{\mathrm{DC} 2}$, then $\mathrm{d}_{2}=\mathrm{d}_{3}=\mathrm{d}_{4}=0, \mathrm{~d}_{1}=1, \mathrm{v}_{\mathrm{o}}=$ $\mathrm{d} \cdot \mathrm{V}_{\mathrm{DC} \text { _isolated }}+\mathrm{V}_{\mathrm{DC} 1}$.

- If $\mathrm{V}_{\mathrm{DC} 2}<\mathrm{v}_{\mathrm{o}}<\mathrm{V}_{\mathrm{DC} 3}$, then $\mathrm{d}_{1}=\mathrm{d}_{3}=\mathrm{d}_{4}=0, \mathrm{~d}_{2}=1, \mathrm{v}_{\mathrm{o}}=$ $\mathrm{d} \cdot \mathrm{V}_{\mathrm{DC} \text { _isolated }}+\mathrm{V}_{\mathrm{DC} 2}$.

- If $\mathrm{V}_{\mathrm{DC} 3}<\mathrm{V}_{\mathrm{o}}<\left(\mathrm{V}_{\mathrm{DC} 3}+\mathrm{V}_{\mathrm{DC} \_ \text {isolated }}\right)$, then $\mathrm{d}_{1}=\mathrm{d}_{2}=\mathrm{d}_{4}=0, \mathrm{~d}_{3}=1$, $\mathrm{V}_{\mathrm{o}}=\mathrm{d} \cdot \mathrm{V}_{\mathrm{DC} \_ \text {isolated }}+\mathrm{V}_{\mathrm{DC} 3}$.

To suitably reproduce all the possible $\mathrm{V}_{\mathrm{o}}$ values, $\mathrm{V}_{\mathrm{DC} 1}, \mathrm{~V}_{\mathrm{DC} 2}$, $\mathrm{V}_{\mathrm{DC}}$ and $\mathrm{V}_{\mathrm{DC} \_ \text {isolated }}$ must satisfy the following conditions:

$$
\mathrm{V}_{\mathrm{DC} \_ \text {isolated }}=\mathrm{V}_{\mathrm{DC} 1} \text {, }
$$




$$
\begin{aligned}
& V_{D C 2}=2 V_{D C 1}, \\
& V_{D C 3}=3 V_{D C 1} .
\end{aligned}
$$

In some cases, the aforementioned circuits can be modified to make it easier to implement the driving of the switching transistors. For instance, the DC/DC converter without galvanic isolation shown in Fig. 7b can be implemented either in the "common ground" configuration or in the "common positive terminal" configuration, as shown in Fig. 8. If the latter option is chosen, then the source terminal of the switching transistors $S_{A}$ and $S_{B}$ will be connected to ground, thus making their driving process easier.

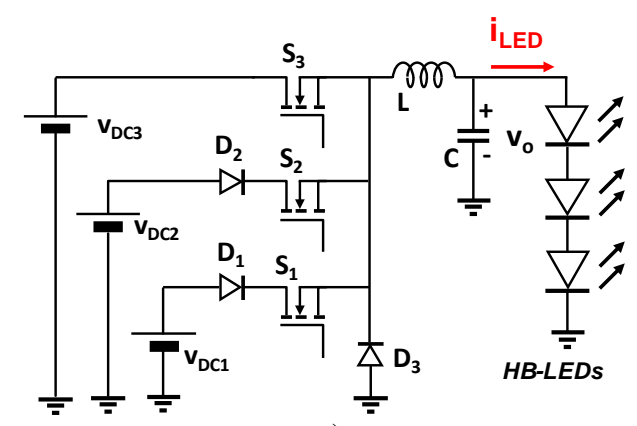

a)

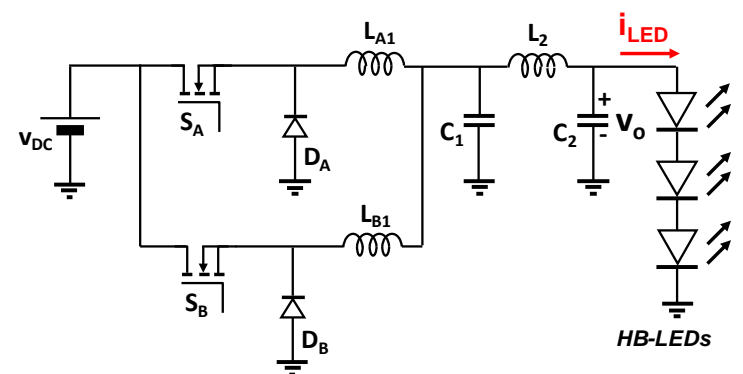

b)

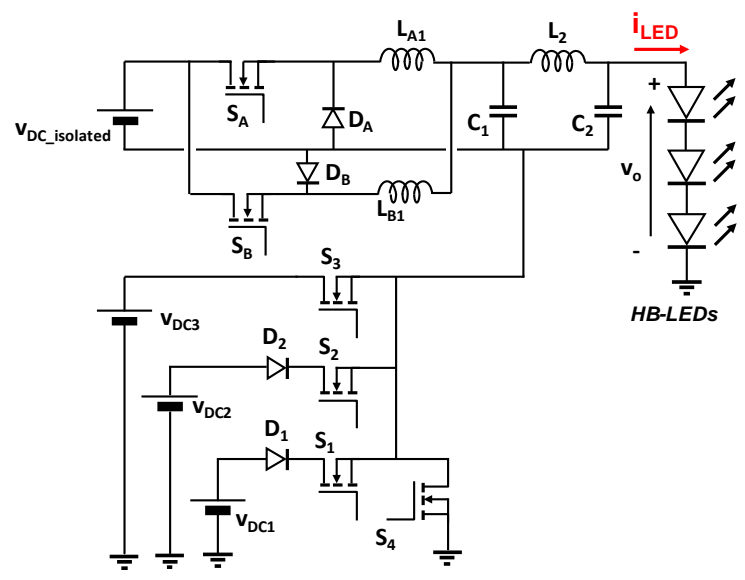

c)

Fig. 7. Examples of suitable fast-response DC/DC converters to be used to synthesize the current passing through an HB-LED string based on DS. a) Multi-Input Buck converter (MIBuck) [44, 45]. b) Two-phase Buck converter with a $4^{\text {th }}$-order filter [47]. c) Floating Multiphase Buck converter [49].
When SCMT or MCMT is used in VLC, the frequencies of the communication signals range from a few $\mathrm{kHz}$ to a few tens of $\mathrm{MHz}$, depending on the bit rate. For the sake of simplicity, let us assume that a carrier of frequency, $\mathrm{f}_{\mathrm{c}}$, is selected to perform an SCMT. The spectrum of the modulated signal is like the one shown in Fig. 9, where $f_{s_{-} \max }$ is the maximum frequency of a significant component in this spectrum. Due to the PWM process in the switches, the voltage at the input of the converter output filter is made up of the aforementioned spectrum, plus other components corresponding to the switching harmonics ( $\mathrm{f}_{\mathrm{Sw}}, 2 \mathrm{f}_{\mathrm{Sw}}, 3 \mathrm{f}_{\mathrm{Sw}}$, etc.) together with their sidebands (in the particular case of multiple-phase converters, the switching harmonics and the sidebands can be attenuated). The converter output filter is responsible for cancelling all the frequency components different from those corresponding to the original signal, i.e., the components around the carrier frequency, $f_{c}$. Thus, the cut-off of this output filter, $\mathrm{f}_{\text {cutoff, }}$, must be high enough to preserve all the components up to frequency $\mathrm{f}_{\mathrm{s}_{-} \max }$ and to cancel out all the components above $\mathrm{f}_{\mathrm{s}_{\_} \max }$, i.e., the components related to the switching harmonics and all the sidebands. In practice, a high-order output filter must be selected to achieve this goal and the switching frequency, $\mathrm{f}_{\mathrm{sw}}$, must be situated 4 or 6 times as high as $f_{s \_ \text {max }}$. The cut-off frequency is selected between these values. Realistic values of the switching frequency are around $4 \mathrm{MHz}$ using power conversion $\mathrm{Si}$ MOSFETs and around $10 \mathrm{MHz}$ using GaN HEMTs (High Electron Mobility Transistors).

To synthesize the output voltage variations up to a few $\mathrm{MHz}$, the switching frequency of the DC/DC converter must be in the $10 \mathrm{MHz}$ range, which is attainable with Si devices. However, higher values of $\mathrm{f}_{\mathrm{s}_{\text {max }}}$ (e.g., in the tens of $\mathrm{MHz}$ range) implies switching frequencies in the $50-100 \mathrm{MHz}$ range, which leads to low efficiency for converters in the $100 \mathrm{~W}$ range. To increase the transient response of the DC/DC converter while keeping the switching frequency at reasonable values, the combination of the switching-mode DC/DC converter with a linear stage can provide certain benefits. This solution has also been explored for ET and EER applications [51-54]. The two most common linear switching combinations are depicted in Figs. 10a and 10b. Series combination (Fig. 10b) is often regarded as less efficient, as all the current through the HB-LEDs has to pass through a dissipative linear stage. However, if the input voltage to this

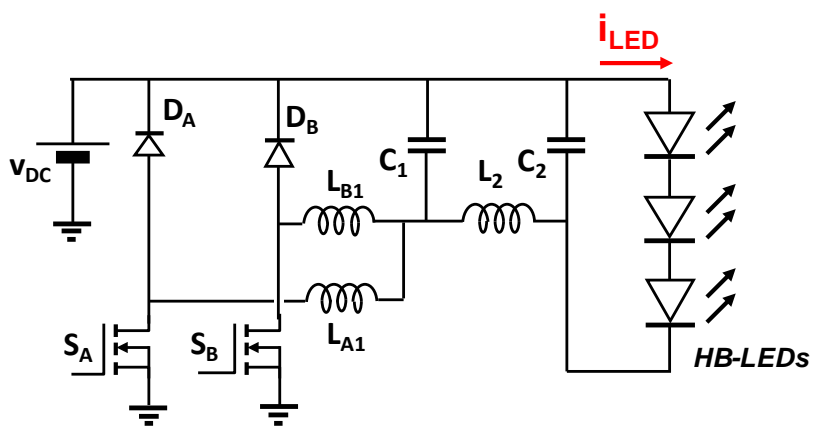

Fig. 8. Modification of the fast-response DC/DC converter shown in Fig. $7 \mathrm{~b}$ in order to have the source terminal of $\mathrm{S}_{\mathrm{A}}$ and $\mathrm{S}_{\mathrm{B}}$ connected to ground. 


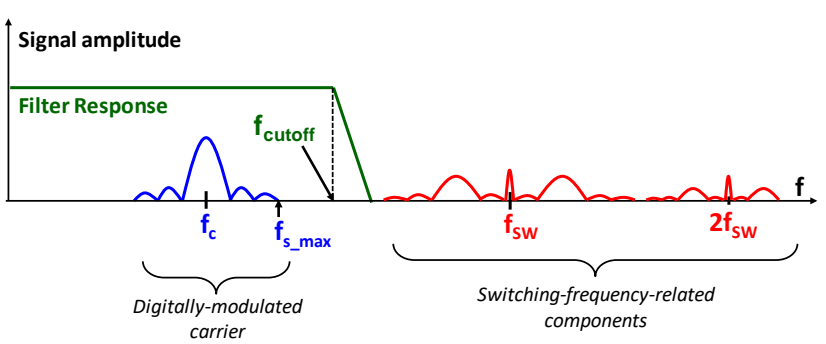

Fig. 9. Spectrum of voltage waveform at the input of the output filter of a switching-mode DC/DC converter that is reproducing a digitally modulated carrier based on DS.

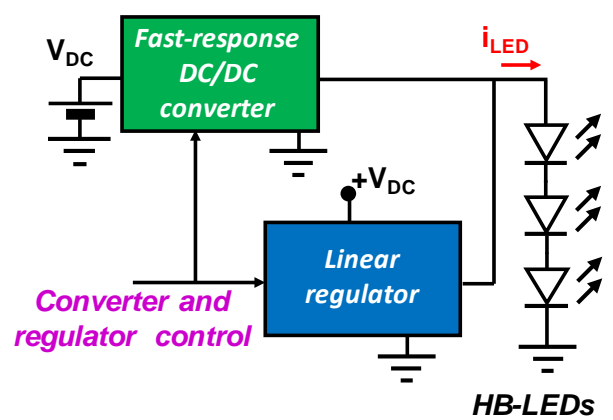

a)

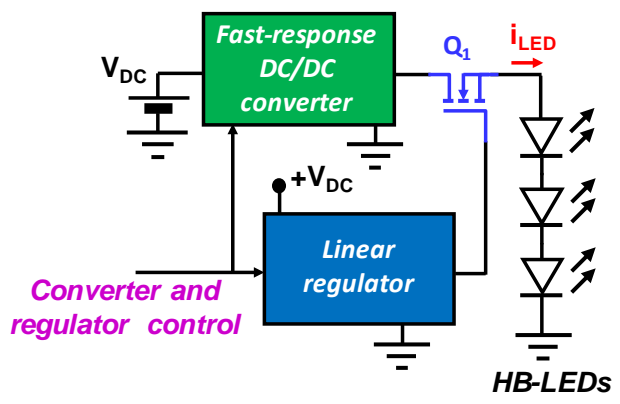

b)

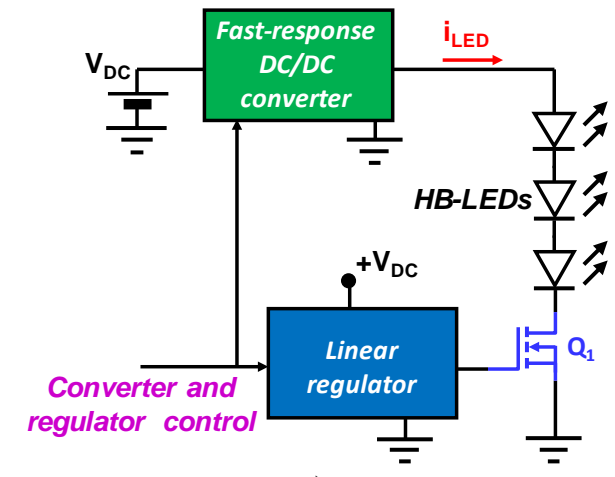

C)

Fig. 10. Using a linear regulator to increase the transient response of a switching-mode DC/DC converter implementing DS. a) Parallel connection. b) Series connection with grounded string cathode. c) Series connection with grounded MOSFET. stage is carefully selected, then it can outperform the parallel combination [55]. One of the main difficulties is to drive transistor $\mathrm{Q}_{1}$, whose source terminal is not connected to ground. However, the HB-LED string can be connected between the output of the switching stage and the drain terminal of $\mathrm{Q}_{1}$, thus allowing the source terminal of $\mathrm{Q}_{1}$ to be connected to ground (see Fig. 10c). This solution is not useful when one of the load terminals has to be connected to ground, which is very common in other types of applications different from driving an HB-LED string.

\section{Fast-response DC/DC converters used to synthesize QAM, ASK or PSK from the converter ripple: Ripple-Based Synthesis}

In any conventional Buck-type DC/DC converter, the output filter must be designed to reject the switching frequency, $\mathrm{f}_{\mathrm{sw}}$. This is also true in the case of the aforementioned fast-response converters used for DS, where the design of the output filter is critical [47]. This is because this filter must function as a passband filter for all the components belonging to the signal to be transmitted (i.e., for frequencies up to $f_{\text {s_max }}$ in Fig. 9), while it must function as a stop-band filter for all the switching harmonics and their side bands, especially for the lower sideband below the switching frequency (see Fig. 9).

In the case of SCMT and when the modulation used is QAM, ASK or PSK, a new solution is possible [56]. The main idea is to use the first switching harmonic as the carrier, modulating both its amplitude and phase in order to reproduce the desired signal. We will call this type of operation Ripple-Based Synthesis (RBS). In this case, the converter output filter is not designed to reject the converter switching frequency, $\mathrm{f}_{\mathrm{sw}}$, and the components around $f_{S w}$ generated by the modulation process, but rather to allow them to reach the HB-LED string. In contrast, however, the second and higher switching harmonics, together with their sidebands, must be rejected by the converter output filter, as shown in Fig. 11. In practice, this means that this filter must be a high order filter. If it is suitably designed, then a sinusoidal waveform plus a DC component can be synthesized at the converter output. In the case of a single-phase DC/DC converter (e.g., a single-phase Buck converter), the amplitude of this sinusoidal waveform cannot be controlled independently from the DC level, because both quantities depend on the converter duty cycle. However, parameters of the sinusoidal waveform, such as its amplitude and phase, can be controlled

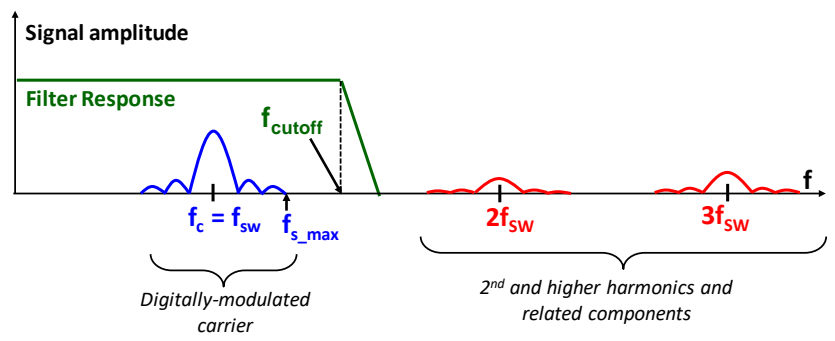

Fig. 11. Spectrum of the voltage waveform at the input of the output filter of a switching-mode DC/DC converter that is reproducing a digitally modulated carrier based on RBS. 


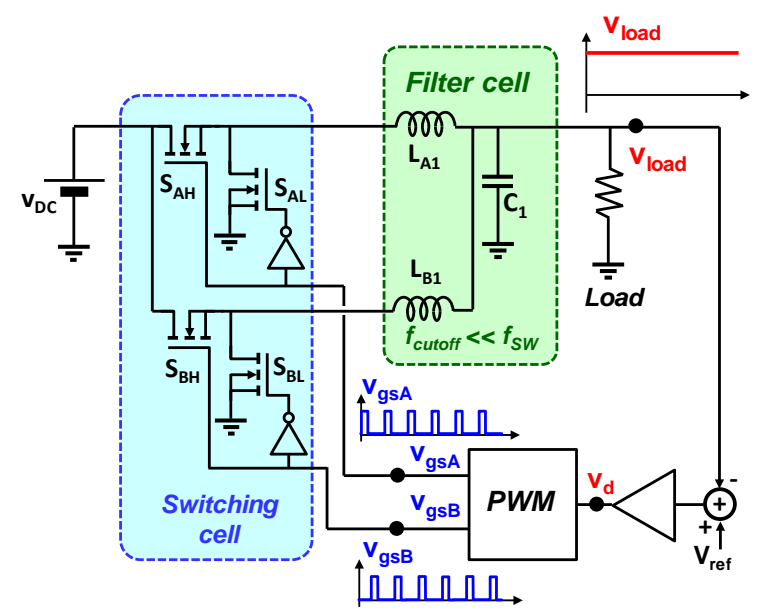

a)

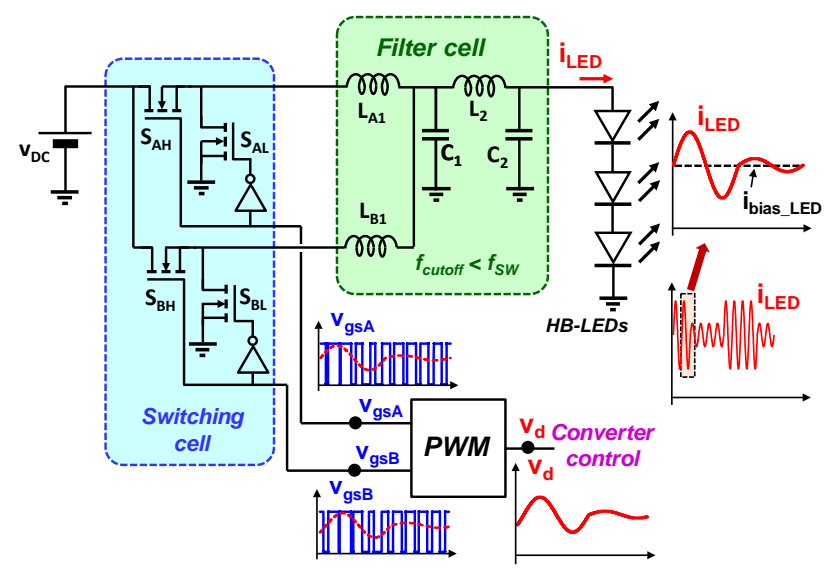

b)

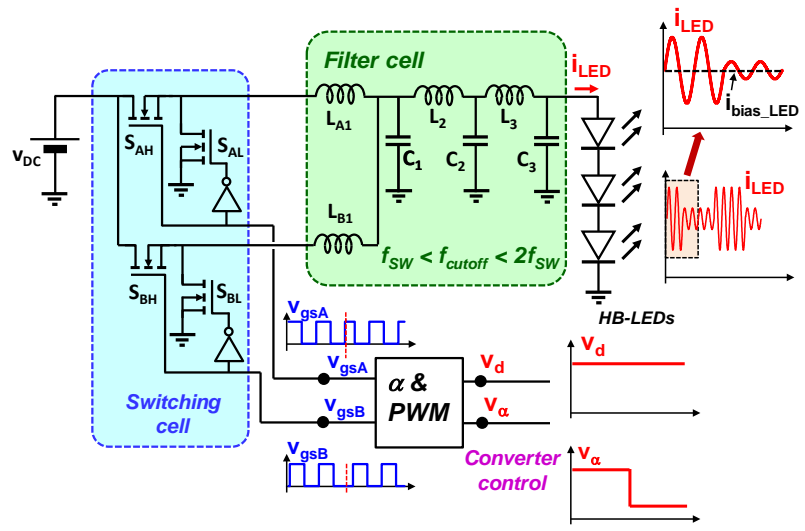

c)

Fig. 12. Examples of two-phase Buck converters. a) Converter for general purpose. b) Converter for SCMT with ASK modulation, using DS. c) Converter for SCMT with ASK modulation, using RBS.

independently from the DC level if the DC/DC converter is a multiphase device and the phase angle of each converter phase is controlled independently.

Fig. 12 shows three two-phase Buck converters designed for different purposes. The two-phase Buck converter shown in Fig. $12 \mathrm{a}$ is a general purpose converter. The two phases were shifted $180^{\circ}$ in order to make the output-voltage filtering easier. The converter duty cycle is constant during steady-state operation and its value is determined by an output-voltage feedback loop.

The two-phase Buck converter shown in Fig. 12b has been designed for VLC based on the DS approach, as explained in the previous section. As the HB-LED string is an almost-constant load, a $4^{\text {th }}$-order filter has been selected to remove all the components above $f_{s_{-} \max }$ (see Fig. 9). As in the previous case, the two phases were shifted $180^{\circ}$. However, the converter duty cycle is constantly changing depending on the waveform that is to be transmitted. For the sake of simplicity, an SCMT with ASK modulation has been represented in Fig. 12b.

To compare DS and RBS, a third two-phase Buck converter is shown in Fig. 12c. The same transmission (i.e., SCMT with ASK modulation) is depicted in this figure. The converter has been implemented with a $6^{\text {th }}$-order output filter. The DC level in the HB-LED string, $\mathrm{i}_{\text {bias-LED, }}$, is controlled by the converter dutycycle, $d$, through voltage $v_{d}$, whereas the amplitude of the AC level in the HB-LED string is determined by $\alpha$, which is the phase-shift between the converter phases, through voltage $\mathrm{v}_{\alpha}$.

As Figs. 12b and 12c show, a lower switching frequency is needed to reproduce the same output current waveform if RBS is used. In practice, the same SCMT can be achieved with a 4-6 times lower switching frequency, which is a highly desirable feature from the point of view of converter efficiency. Moreover, not only ASK modulation can be implemented, but also PSK and QAM modulations can be achieved if not only the phase-shift between the converter phases, $\alpha$, is considered, but also the average phase of both phases, $\beta$, is controlled. The main drawback of RBS compared to DS is that the former method is mainly used to synthesize SCMT, as its capability to perform MCMT has not been demonstrated.

Finally, we wish to remark that the converter shown in Fig. 12c has already been proven to synthesize a SCMT with 64QAM over a string of HB-LEDs [56]. In this case, not only the phase-shift, $\alpha$, is controlled (as appears in Fig. 12c), but also the average phase, $\beta$.

\section{Fast-response DC/DC converters used as Envelope Amplifiers for RFPAs used in VLC}

As previously stated, ET and EER techniques have been proposed either to increase the efficiency of linear RFPAs (in the case of ET) or to achieve a linear RFPA from an efficient non-linear switching-mode RFPA (in the case of EER). These techniques can be directly used to finally achieve an efficient linear RFPA, as shown in the general schemes shown in Fig. 2b, Fig. 3d, Fig. 4a, Fig. 4b and Fig. 5a.

The use of these techniques in VLC is depicted in Fig. 13. To illustrate the differences between both techniques, the 8QAM signal, v8QAM, shown in Fig. 14a will be considered. From this waveform, the value of its envelope, $v_{\text {env }}$, and a waveform with the information of its phase, $\mathrm{v}_{\phi}$, can be obtained from a peak detector and a comparator, respectively (this information can often be obtained directly from the modulation process). 


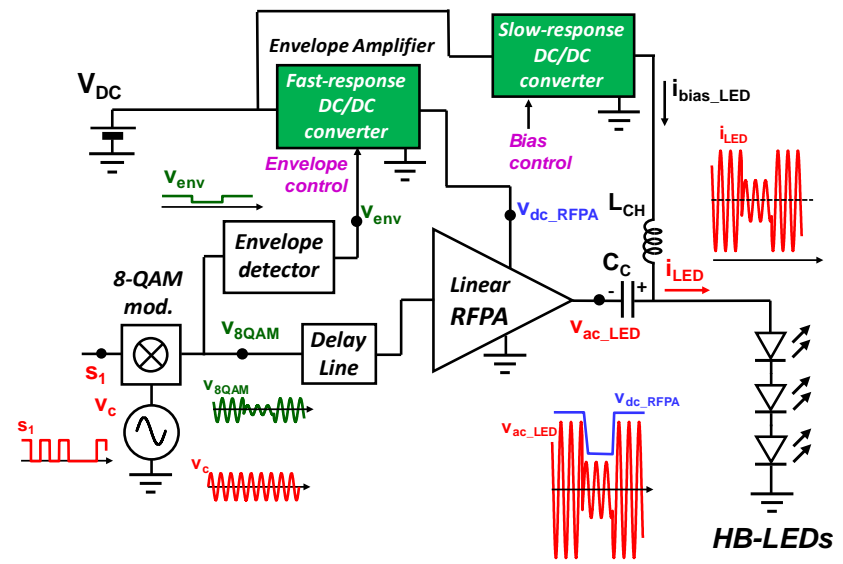

a)

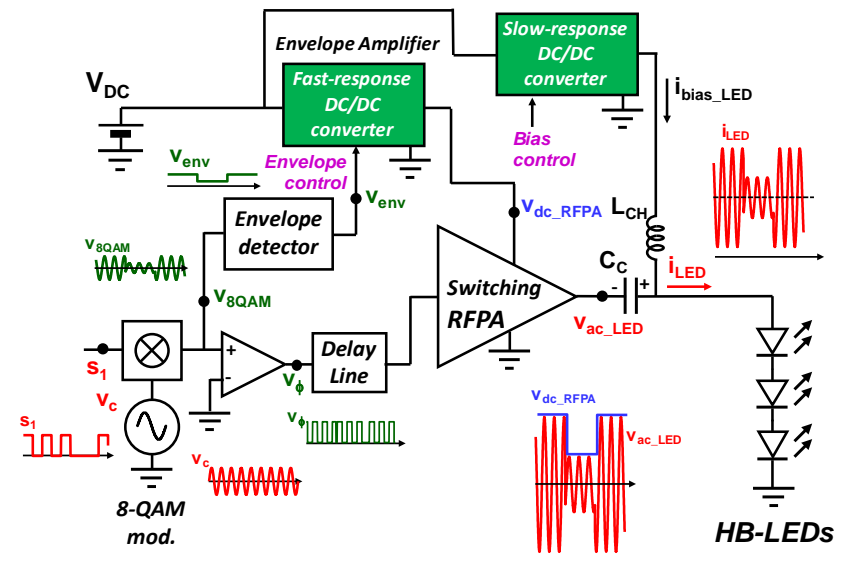

b)

Fig. 13. Achieving an efficient linear RFPA for VLC with the help of fastresponse DC/DC converters. a) ET technique. b) EER technique.

Signal $\mathrm{v}_{\text {env }}$ is used in both techniques to determine the control signal of the Envelope Amplifier, which generates a high power version of $v_{\text {env }}$ (labeled as $\mathrm{V}_{\mathrm{dc} \_ \text {RFPA }}$ ) that is actually the varying voltage used to supply power to the RFPA. On the other hand, the voltage at the input port of the RFPA is different in both techniques: it is a delayed version of $\mathrm{V}_{8 \mathrm{QAM}}$ in ET techniques, while it is $\mathrm{v}_{\phi}$ (a signal with only phase information, also suitably delayed) in the case of EER techniques.

It should be noted that the fast-response DC/DC converter must be fast enough to reproduce the variation in the envelope of the modulated signal (the envelope of the 8-QAM in our example). This is a big difference with respect to the fastresponse DC/DC converter needed for DS, according to Fig. 6. However, the same topologies as those proposed to implement the solution shown in Fig. 6 (e.g., the converters depicted in Fig. 7) can be used here, though replacing the HB-LEDs with the RFPA. An example based on a two-phase Buck converter used as an Envelope Amplifier [47] and a conventional Buck converter for biasing the HB-LED string is shown in Fig. 15.

When using fast-response DC/DC converters to implement the Envelope Amplifier needed to apply ET or EER techniques, the bandwidth limitations of these converters can be overcome

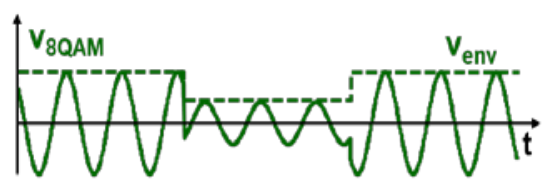

a)

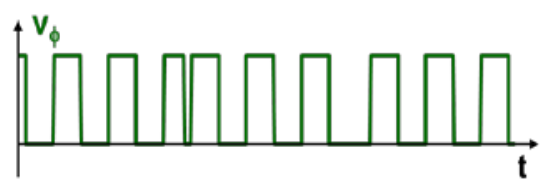

b)

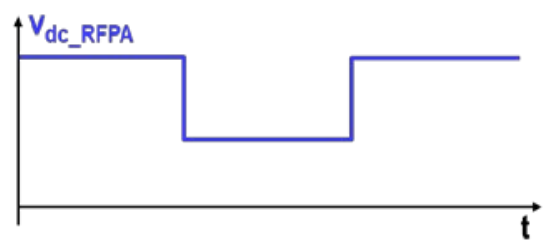

c)

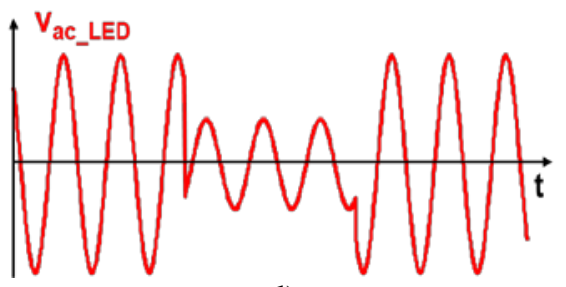

d)

Fig. 14. Example of an 8-QAM signal. a) Original signal and its envelope. b) Signal containing the phase information. c) Voltage at the output of the Envelope Amplifier. d) AC component of the voltage across the HB-LED string.

by the use of linear-assisted solutions, as previously proposed for the same type of converters when performing DS (see Fig.

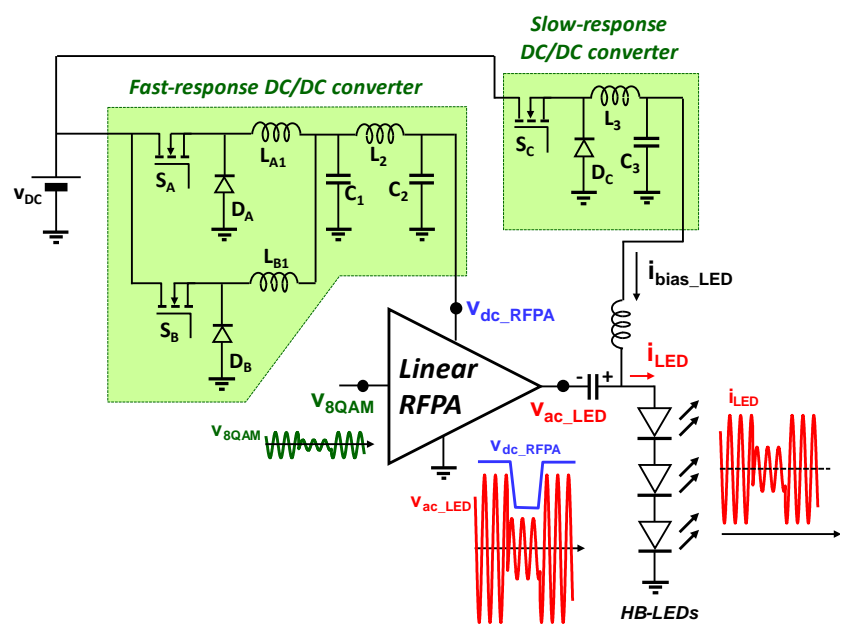

Fig. 15. A two-phase Buck converter used to increase the efficiency of an RFPA used in VLC. Moreover, a conventional Buck converter is used to bias the HB-LED string. The waveforms correspond to an SCMT using 8QAM and applying the ET technique. 


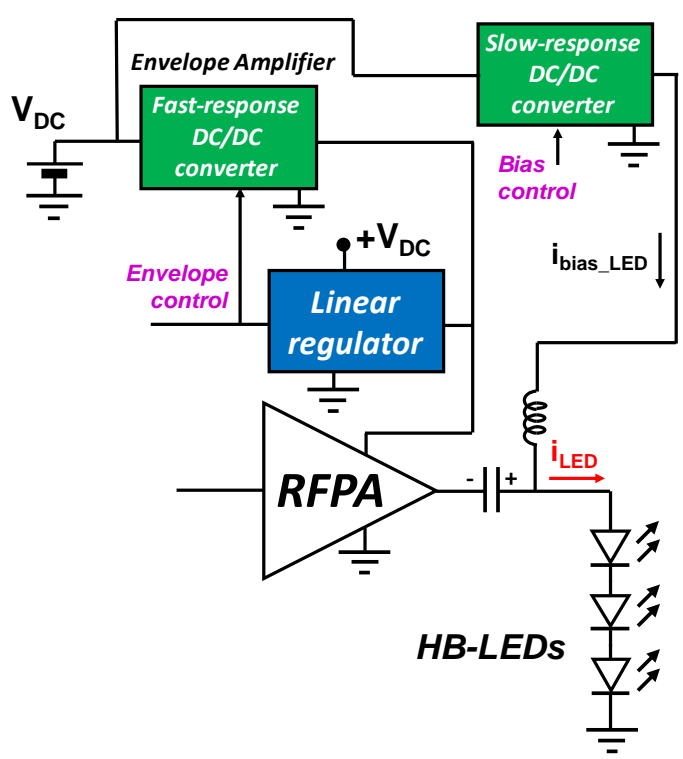

Fig. 16. Parallel connection of a linear regulator used to increase the transient response of a switching-mode DC/DC converter that works as Envelope Amplifier in a VLC system. Either the RFPA efficiency or linearity is increased by using ET or EER techniques.

10a and Fig. 10b). An example, with a linear regulator connected in parallel, is depicted in Fig. 16.

Finally, efficient linear RFPAs obtained using ET and ERR techniques can be used in MCMT, according to the possible implementations given in Fig. 3d, Fig. 4a and Fig. 4b.

\section{EXPERIMENTAL RESULTS}

The experimental results are divided into the characterization of HB-LEDs for VLC and a summary of the results obtained in three examples of VLC transmitters. DS is used to generate a test waveform and an MCMT in two of them, whereas RBS is implemented in the third VLC transmitter to perform an SCMT.

\section{A. HB-LEDs characterization}

In order to use an HB-LED for VLC, both its equivalent dynamic resistance (defined as the slope of the I-V curve near the operating point) and its bandwidth need to be taken into account. The equivalent dynamic resistance can be easily obtained from the device datasheet, whereas no information regarding the HB-LED bandwidth is usually provided.

To characterize the bandwidth of the selected HB-LED (W42180, from Seoul Semiconductor) for VLC, a simple Class A amplifier (depicted in Fig. 17a) was built. The AC component of $\mathrm{v}_{\mathrm{gs}}$ comes from a HP-3598A Spectrum-Network Analyzer. The current through the HB-LED is sensed using a $2.5 \Omega$ resistor. The transconductance between $\mathrm{V}_{\mathrm{gs}}$ and the $\mathrm{AC}$ component of $i_{\text {LED }}$ is shown in Fig. 18a. It can be seen that the 3 $\mathrm{dB}$ bandwidth ranges between 1 and $20 \mathrm{MHz}$.

In order to provide good illumination levels, several HBLEDs need to be connected together in series and/or in parallel.

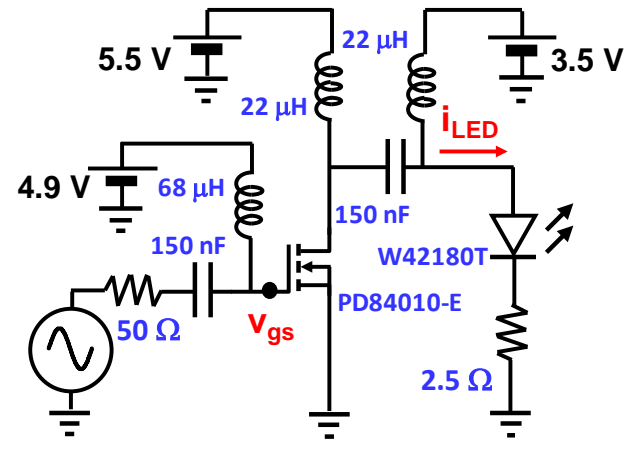

a)

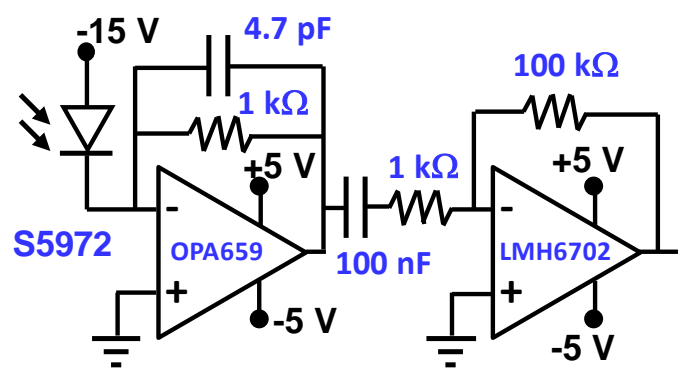

b)

Fig. 17. a) Circuit to measure the bandwidth of an HB-LED. b) Optical receiver.

This combination affects the transmission bandwidth, as shown in Fig. 18a.

The aforementioned measurements reveal the transconductance bandwidth of the system made up of the amplifier and the HB-LEDs. However, the bandwidth of the VLC system includes the HB-LEDs' ability to transform current into light, and the optical receiver response. It should be noted that white HB-LEDs usually have a phosphorus layer that converts the blue light emitted by the semiconductor into white light suitable for illumination. In order to compute the complete VLC bandwidth, the frequency response of this phosphorus should be taken into account. Alternatively, a blue filter can be used to block all the light spectral components provided by the phosphorus, leaving only the blue light generated by the semiconductor. As to the optical receiver, a suitable Photo Diode (PD) must be selected. Note that, in practice, the HB-LED bandwidth is the limiting factor in the VLC system. The final optical receiver used to measure the bandwidth of the VLC system can be seen in Fig. 17b, where the PD is an S5972 (from Hamamatsu), whose bandwidth is well above that expected for the HB-LED string. The HP-3598A (used as a Network Analyzer) is connected to the gate of the MOSFET and to the output of the optical receiver. The experimental results thus obtained are shown in the Bode plot in Fig. 18b. These results were obtained with a distance of $10 \mathrm{~cm}$ between transmitter and receiver. A slope of about $-5 \mathrm{~dB}$ per decade was measured in this plot when using a blue light filter (from Chris James). In a real case, this slope could be partially compensated at the signal 


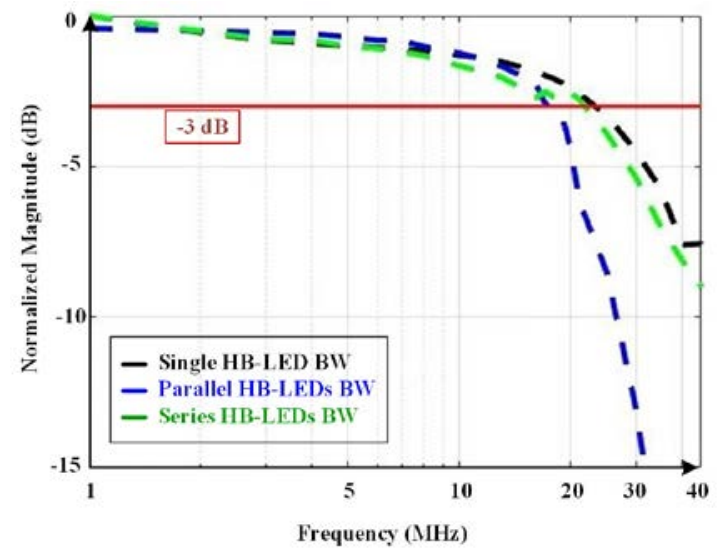

a)

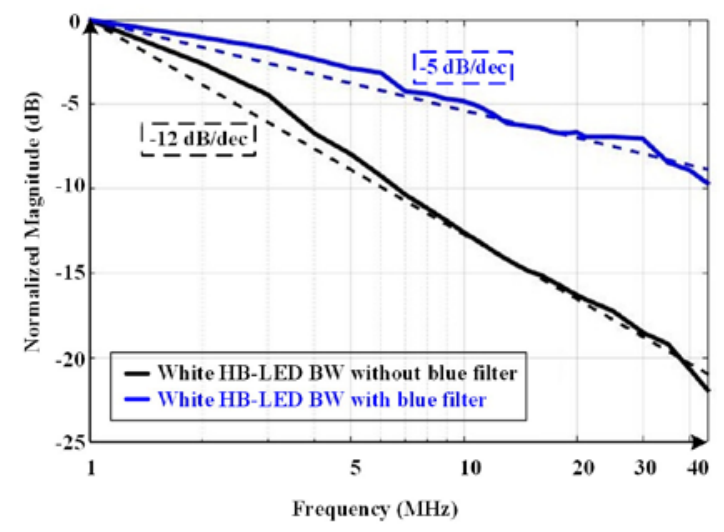

b)

Fig. 18. Frequency response measurements. a) Transconductance between $\mathrm{v}_{\mathrm{gs}}$ and the AC component of $\mathrm{i}_{\mathrm{LED}}$. b) Complete VLC Bode plot with and without a blue filter.

processing stage. The bandwidth obtained with this filter is clearly broader than that obtained without a filter. However, it should be noted that the plots shown in Fig. 18b have been normalized at their low frequency response value, the actual magnitude of the plot obtained with the blue filter being $15 \mathrm{~dB}$ below the value obtained without the blue filter. These results are in line with those reported by other researchers [26, 27].

\section{B. Results obtained from three prototypes of two-phase Buck converters}

Three two-phase Buck derived converter prototypes were built and tested to be used in VLC. The main characteristics of these prototypes are summarized in Table 1 . In all cases, the average current passing through the HB-LED string was maintained below $500 \mathrm{~mA}$. This means a luminous flux of around $100 \mathrm{~lm}$ per HB-LED. Prototype \#1 corresponds to the circuit given in Fig. 7b. It was used to drive a string of 5 W42180T HB-LEDs in series connection (see Fig. 19a). The desired waveform (a test one) is generated by DS. The DC/DC converter implementation is the same as the one presented in [47], the only differences being the switching frequency $(5 \mathrm{MHz}$ in this case) and the value of the reactive components of the output filter (cut-off frequency at $1.3 \mathrm{MHz}$ ): $\mathrm{L}_{\mathrm{A} 1}=\mathrm{L}_{\mathrm{B} 1}=3.15$

\begin{tabular}{|c|c|c|c|c|c|c|c|}
\hline Prototype & $\begin{array}{l}\text { Waveform/ } \\
\text { Modulation } \\
\text { scheme }\end{array}$ & $\begin{array}{l}\mathrm{f}_{\mathrm{s} \text { max }} \\
{[\mathrm{IMHz}}\end{array}$ & $\begin{array}{l}\mathrm{f}_{\mathrm{SW}} \\
{[\mathrm{MHz}]}\end{array}$ & Output filter & $\begin{array}{l}\mathbf{f}_{\text {cutoff }} \\
\text { [MHz] }\end{array}$ & $\begin{array}{l}\text { Number of LEDs } \\
\text { (average power) }\end{array}$ & $\begin{array}{l}\text { Average } \\
\text { efficiency }\end{array}$ \\
\hline$\# 1$ & $\begin{array}{c}\text { Test } \\
\text { waveform }\end{array}$ & 1 & 5 & $\begin{array}{l}4^{\text {th }} \text {-order } \\
\text { Legendre }\end{array}$ & 1.3 & $\begin{array}{c}5 \\
(6.7 W)\end{array}$ & $90 \%$ \\
\hline$\# 2$ & $\begin{array}{l}\text { 64-QAM- } \\
\text { OFDM }\end{array}$ & 3.1 & 10 & $\begin{array}{l}4^{\text {th }} \text {-order } \\
\text { Butterworth }\end{array}$ & 4 & $\begin{array}{c}6 \\
(8 W)\end{array}$ & $91 \%$ \\
\hline$\# 3$ & 64-QAM & 0.67 & 0.5 & $\begin{array}{l}6^{\text {th }} \text {-order } \\
\text { Butterworth }\end{array}$ & 0.75 & $\begin{array}{c}6 \\
(8 W)\end{array}$ & $86 \%$ \\
\hline
\end{tabular}

Table 1. Main characteristics of the three prototypes.

$\mu \mathrm{H}, \mathrm{C}_{1}=25.4 \mathrm{nF}, \mathrm{L}_{2}=1.39 \mu \mathrm{H}$ and $\mathrm{C}_{2}=9.49 \mathrm{nF}$. The test waveform used to check the converter operation is made up of the three first harmonics of a $200 \mathrm{kHz}$ square wave signal (components of $200 \mathrm{kHz}, 600 \mathrm{kHz}$ and $1 \mathrm{MHz}$ ). The results are given in Fig. 19b. The trace in blue is the voltage applied to the HB-LED string, while the trace in yellow is the output of the VLC receiver.

Prototype \#2 is described in $[57,58]$. The power converter topology is shown in Fig. 20. It is a modification of the one shown in Fig. 8 (the HB-LED string is powered by the series connection of this converter and a conventional Buck converter,

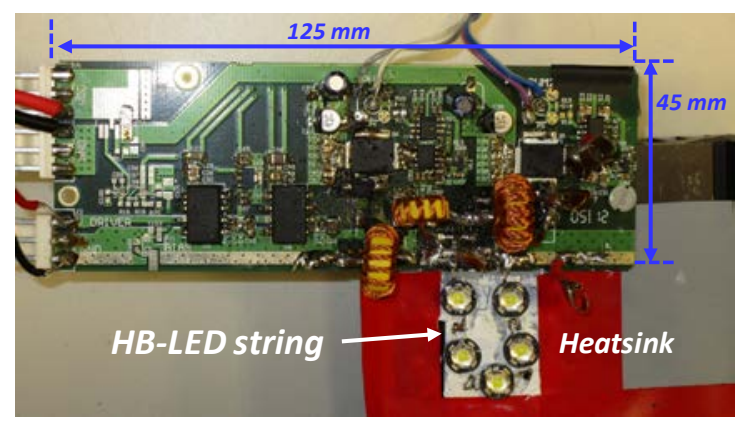

a)

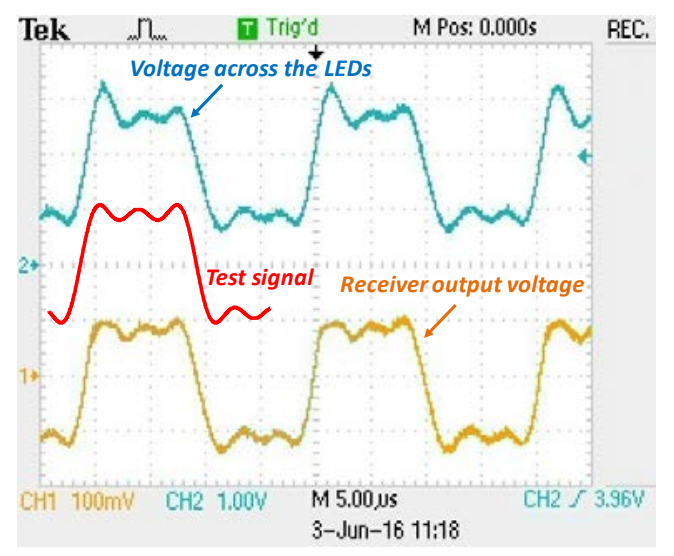

b)

Fig. 19. a) Prototype of a Two-phase Buck converter designed to drive a string of 5 HB-LEDs using DS (Prototype \#1). b) Waveforms obtained reproducing a test signal with components of $200 \mathrm{kHz}, 600 \mathrm{kHz}$ and 1 MHz. The trace in blue is the voltage applied to the HB-LEDs and the trace in yellow is the output voltage of the VLC receiver of Fig 17b. 


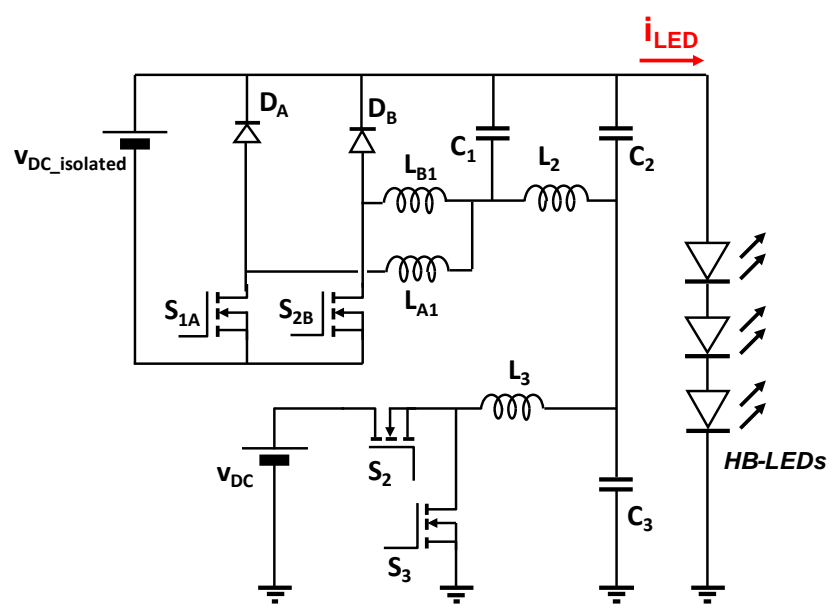

Fig. 20. Converter studied in $[57,58]$. The upper part of this converter is switching at high frequency $(10 \mathrm{MHz})$, whereas the lower part is switching at $250 \mathrm{kHz}$.

which is responsible for generating the main part of the DC level). It performs an MCMT, with a 64-QAM-OFDM, using DS, $3.1 \mathrm{MHz}$ being the component of the highest frequency that must be suitably transmitted. The results are given in Fig. 21, where the received and transmitted signals are compared. The study of the dimming process for this converter is given in [58]. This study shows how the level of the AC current passing through the HB-LED must be changed in line with the dimming in order to maintain linear operation in the LED. Otherwise, an increase in the root mean square value of the Error Vector Magnitude (EVM $\mathrm{EMS}_{\mathrm{S}}$ ) takes place. This converter allows us to obtain efficiencies of around $90-93 \%$, with a bit rate of about 10 Mbps, using a $10 \mathrm{~W}$ string of standard HB-LEDs as transmitter. The converter uses Si transistors switching at $10 \mathrm{MHz}$ (upper part of this converter) and at $250 \mathrm{kHz}$ (lower part).

Finally, an SCMT is generated using RBS in Prototype \#3 $[56,59]$. The modulation used is 64-QAM. As the switching frequency is $500 \mathrm{kHz}$ (Table 1), the component of the highest frequency that can be transmitted is slightly higher than this frequency (it is the upper sideband, whose highest frequency

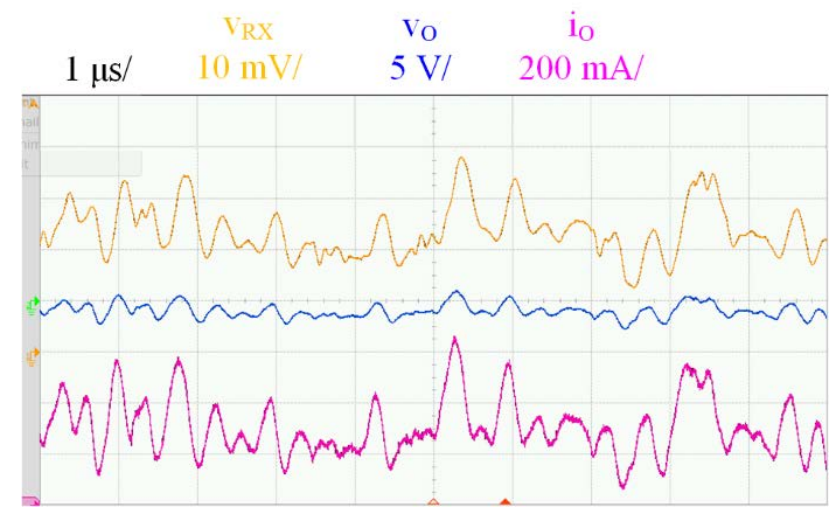

Fig. 21. a) Main waveform in Prototype \#2. The trace in yellow $\left(v_{R X}\right)$ is the received signal, the trace in blue $\left(\mathrm{v}_{\mathrm{O}}\right)$ is the voltage across the HBLED string and the trace in pink (io) is the current passing through the HB-LED string.

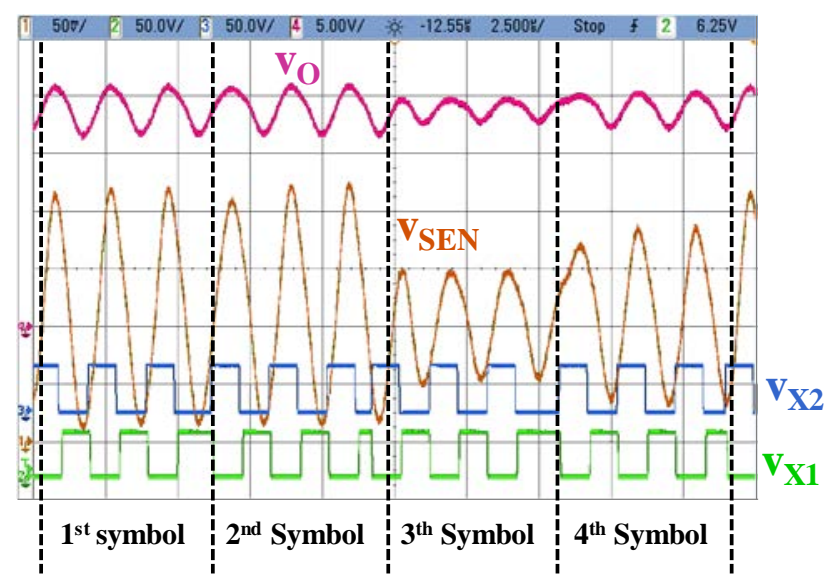

a)

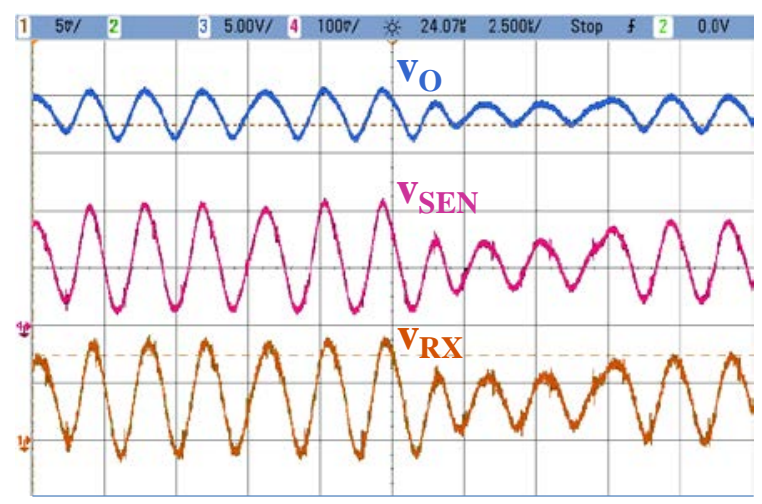

b)

Fig. 22. a) Main waveform in Prototype \#3. $v_{O}$ is the output voltage, $v_{S E N}$ is a replica of the output current and $v_{X_{1}}$ and $v_{X_{2}}$ are the switch-node voltages. b) Comparison between the transmitting waveform ( $v_{O}$ and $\left.v_{S E N}\right)$ and the received waveform $\left(\mathrm{v}_{\mathrm{RX}}\right)$.

component is around $670 \mathrm{kHz}$ ). The converter topology is the one given in Fig. 12c, but the control circuitry includes the variation of the average phase, $\beta$, to perform QAM. Some illustrative waveforms of the process to generate the modulation from the square waveforms at the switch-nodes are given in Fig. 22a, while Fig. 22b shows waveforms to compare the received and transmitted signals.

\section{CONCLUSIONS}

Power electronics plays a very important role in maintaining high efficiency in lighting devices when they are used in VLC. Fast response DC/DC converters can help in this task in several different ways:

- They are able to synthesize the desired current waveform passing through the HB-LED string (both the bias and the AC components) by suitably changing its duty cycle. As in any conventional converter, the switching frequency ripple must be removed at the output port, but the output filter must behave as a band-pass filter for the waveform that is to be synthesized. 
- They are able to synthesize digital modulations such as ASK, PSK and QAM from the non-removed output voltage ripple. The implementation of this option implies the use of a two-phase Buck converter. In this case, the duty cycle determines the bias current, while the amplitude and phase of the modulated signal is determined by the phases of the control signals.

- They work as Envelope Amplifiers to achieve an efficient linear RFPA from either a non-efficient linear RFPA (ET technique) or an efficient non-linear RFPA (EER technique). In this case, another slow-response DC/DC converter is responsible for the biasing task, while the RFPA is responsible for boosting the modulated signal to the desired level.

The experimental results demonstrate that bandwidths in the range of a few $\mathrm{MHz}$ for transmitting complex signals, like 64QAM, can be achieved with the appropriate design of two-phase Buck converters with high-order output filters. Output power levels of around $10 \mathrm{~W}$ and measured efficiencies in the range of $90 \%$ can be achieved, switching the converter at frequencies below $10 \mathrm{MHz}$. These results demonstrate that both efficient illumination and quite high data rates are possible employing very simple hardware.

\section{ACKNOWLEDGEMENTS}

This work has been supported by the Spanish Government under Project MINECO-17-DPI2016-75760-R and the scholarship FPU14/03268, as well as by the Principality of Asturias Regional Government under Project FC-15-GRUPIN14-143, Project SV-PA-17-RIS3-4 and by European Regional Development Fund (ERDF) grants.

\section{REFERENCES}

[1] M. Kleeman, "Point of View: Wireless Point of Disconnect", 2011, Global Info. Industry Center.

[2] GBI Research, Visible Light Communication (VLC)-A Potential Solution to the Global Wireless Spectrum Shortage, Sep. 2011 [Online].

[3] S. Rajagopal, R. D. Roberts and S. K. Lim, "IEEE 802.15.7 visible light communication: modulation schemes and dimming support," in IEEE Communications Magazine, vol. 50, no. 3, pp. 72-82, March 2012.

[4] H. Hass, "Li-Fi modulation and networked $\mathrm{Li}-\mathrm{Fi}$ attocell concept”, tutorial, 2013.

[5] Y. Tanaka, T. Komine, S. Haruyama and M. Nakagawa, "Indoor visible light data transmission system utilizing white LED lights", in IEICE Transacions on Communication, vol. E86-B, no. 8, pp. 2440-2454, August 2003.

[6] T. Komine and M. Nakagawa, "Fundamental analysis for visiblelight communication system using LED lights", in IEEE Transactions on Consumer Electronics, vol. 50, no. 1, pp. 100107, February 2004.

[7] Y. Tanaka, T. Komine, S. Haruyama and M. Nakagawa, "Indoor visible communication utilizing plural white LEDs as lighting”, in IEEE International Symposium on Personal, Indoor and Mobile Radio Communications, San Diego, 2001, pp. F-81-F85.
[8] S. K. Liaw, H. H. Chou, C. J. Wu, M. J. Chien and C. Teng, "500 $\mathrm{Mb} / \mathrm{s}$ OOK visible light communications using RGB-based LEDs," International Symposium on Next-Generation Electronics (ISNE), Taipei, 2015, pp. 1-2.

[9] A. Jovicic, J. Li and T. Richardson, "Visible light communication: opportunities, challenges and the path to market”, in IEEE Communications Magazine, vol. 51, no. 12, pp. 26-32, December 2013.

[10] Y. Tanaka, S. Haruyama and M. Nakagawa, "Wireless optical transmissions with white colored LED for wireless home links", in EEE International Symposium on Personal, Indoor and Mobile Radio Communications, London, 2001, pp 1325-1329.

[11] T. Komine and M. Nakagawa, "Integrated system of white LED visisble-light communication and power-line communication”, in IEEE Transactions on Consumer Electronics, vol. 49, no. 1, pp. 71-79, February 2003.

[12] T. Komine, S. Haruyama and M. Nakagawa, "Performance evaluation of narrowband OFDM on integrated system of Power Line communication and visible light wireless communication”, in International Symposium on Wireless Pervasive Computing, Phuket 2006.

[13] M. Z. Afgani, H. Haas, H. Elgala and D. Knipp, "Visible light communication using OFDM", in International Conference on Testbeds and Research Infrastructures for the Development of Networks and Communities, Barcelona, 2006.

[14] O. González, R. Pérez-Jiménez, S. Rodríguez, J. Rabadán and A. Ayala, "Adaptive OFDM system for communications over the indoor wireless optical channel”, in IEE ProceedingsOptoelectronics, vol. 153, no. 4, pp. 139-144, August 2006.

[15] S. K. Hashemi, Z. Ghassemlooy, L. Chao and D. Benhaddou, "Channel estimation for indoor diffuse optical OFDM wirelees communications", in International Conference on Broadband Communications, Networks and Systems, London 2008, pp. 431434.

[16] A. H. Azhar, T. A. Tran and D. O’Brien, “A gigabit/s indoor wireless transmission using MIMO-OFDM visible-light communications", in IEEE Photonics Technology Letters, vol. 25, no. 2, pp. 171-174, January 2013.

[17] H. Elgala, R. Mesleh and H. Haas, "Practical considerations for indoor wireless optical system implementation using OFDM," International Conference on Telecommunications, Zagreb 2009, pp. 25-29.

[18] M. S. A. Mossaad, S. Hranilovic and L. Lampe, "Visible Light Communications Using OFDM and Multiple LEDs," in IEEE Transactions on Communications, vol. 63, no. 11, pp. 4304-4313, Nov. 2015.

[19] S. Dimitrov, S. Sinanovic and H. Haas, "Clipping Noise in OFDM-Based Optical Wireless Communication Systems," in IEEE Transactions on Communications, vol. 60, no. 4, pp. 10721081, April 2012.

[20] I. Stefan, H. Elgala, R. Mesleh, D. O'Brien and H. Haas, "Optical Wireless OFDM System on FPGA: Study of LED Nonlinearity Effects," IEEE Vehicular Technology Conference (VTC Spring), 2011, Yokohama, 2011, pp. 1-5.

[21] J. Armstrong, "OFDM for Optical Communications," in Journal of Lightwave Technology, vol. 27, no. 3, pp. 189-204, Feb. 2009.

[22] Yuanquan Wang et al., "875-Mb/s asynchronous bi-directional 64QAM-OFDM SCM-WDM transmission over RGB-LEDbased visible light communication system," Optical Fiber 
Communication Conference and Exposition and the National Fiber Optic Engineers Conference (OFC/NFOEC), Anaheim, CA, 2013, pp. 1-3.

[23] S. Rajbhandari, H. Chun, G. Faulkner, K. Cameron, A.V.N. Jalajakumari, R. Henderson, D. Tsonev, M. Ijaz, Z. Chen. Z, H. Haas, E. Xie; J.J.D. McKendry, J. Herrnsdorf, E. Gu, M. D Dawson and D. O'Brien, "High-Speed Integrated Visible Light Communication System: Device Constraints and Design Considerations", in IEEE Journal on Selected Areas in Communications, vol.33, no.9, pp.1750-1757, Sept. 2015.

[24] T. Fath, C. Heller and H. Haas, "Optical Wireless Transmitter Employing Discrete Power Level Stepping”, in Journal of Lightwave Technology, vol. 31, no. 11, pp. 1734-1743, June, 2013.

[25] H. Chun et al., "Visible Light Communication Using a Blue GaN $\mu \mathrm{LED}$ and Fluorescent Polymer Color Converter," in IEEE Photonics Technology Letters, vol. 26, no. 20, pp. 2035-2038, October 2014.

[26] H. Le Minh et al., "80 Mbit/s Visible Light Communications using pre-equalized white LED," 34th European Conference on Optical Communication, Brussels, 2008, pp. 1-2.

[27] H. Le Minh et al., "100-Mb/s NRZ Visible Light Communications Using a Postequalized White LED," in IEEE Photonics Technology Letters, vol. 21, no. 15, pp. 1063-1065, Aug. 2009.

[28] J. Vucic, C. Kottke, S. Nerreter, A. Buttner, K. D. Langer and J. W. Walewski, "White Light Wireless Transmission at 200+ Mb/s Net Data Rate by Use of Discrete-Multitone Modulation," in IEEE Photonics Technology Letters, vol. 21, no. 20, pp. 15111513, Oct. 2009.

[29] J. Vucic, C. Kottke, S. Nerreter, K. D. Langer and J. W. Walewski, "513 Mbit/s Visible Light Communications Link Based on DMT-Modulation of a White LED," in Journal of Lightwave Technology, vol. 28, no. 24, pp. 3512-3518, Dec. 2010.

[30] J. Vučić, C. Kottke, K. Habel and K. D. Langer, "803 Mbit/s visible light WDM link based on DMT modulation of a single RGB LED luminary," Optical Fiber Communication Conference and Exposition and the National Fiber Optic Engineers Conference (OFC/NFOEC), Los Angeles, CA, 2011, pp. 1-3.

[31] A. M. Khalid, G. Cossu, R. Corsini, P. Choudhury and E. Ciaramella, "1-Gb/s Transmission Over a Phosphorescent White LED by Using Rate-Adaptive Discrete Multitone Modulation," in IEEE Photonics Journal, vol. 4, no. 5, pp. 1465-1473, Oct. 2012.

[32] C. Kottke, J. Hilt, K. Habel, J. Vučić and K. D. Langer, "1.25 Gbit/s visible light WDM link based on DMT modulation of a single RGB LED luminary," 2012 38th European Conference and Exhibition on Optical Communications, Amsterdam, 2012, pp. 13.

[33] H. Le Minh et al., "A 1.25-Gb/s Indoor Cellular Optical Wireless Communications Demonstrator," in IEEE Photonics Technology Letters, vol. 22, no. 21, pp. 1598-1600, Nov. 2010.

[34] L. Hanzo, W. Webb and T. Keller, "Single- and Multi-Carrier Quadrature Amplitude Modulation”, 2000, Wiley.

[35] S. Zhao, J. Xu and O. Trescases, "A dimmable LED driver for visible light communication (VLC) based on LLC resonant DC-
DC converter operating in burst mode," IEEE Applied Power Electronics Conference and Exposition, Long Beach, CA, 2013, pp. 2144-2150.

[36] J. G. Proakis, “Digital Communications,” 4th ed. New York: McGrawHill, 2000.

[37] X. Deng, Y. Wu, K. Arulandu, G. Zhou and J. P. M. G. Linnartz, "Performance comparison for illumination and visible light communication system using buck converters," IEEE Globecom Workshops (GC Wkshps), Austin, TX, 2014, pp. 547-552.

[38] K. Modepalli and L. Parsa, "Dual-Purpose Offline LED Driver for Illumination and Visible Light Communication," in IEEE Transactions on Industry Applications, vol. 51, no. 1, pp. 406419, Jan.-Feb. 2015.

[39] A. Tsiatmas, F. M. Willems, J. P. M. Linnartz, S. Baggen and J. W. Bergmans, "Joint illumination and visible-Light Communication systems: Data rates and extra power consumption," 2015 IEEE International Conference on Communication Workshop (ICCW), London, 2015, pp. 13801386.

[40] F. H. Raab et al., "Power amplifiers and transmitters for RF and microwave," in IEEE Transactions on Microwave Theory and Techniques, vol. 50, no. 3, pp. 814-826, Mar. 2002.

[41] P. Cheng, M. Vasić, O. García, J. A. Oliver, P. Alou and J. A. Cobos, "Minimum Time Control for Multiphase Buck Converter: Analysis and Application," in IEEE Transactions on Power Electronics, vol. 29, no. 2, pp. 958-967, Feb. 2014.

[42] V. Yousefzadeh, E. Alarcón and D. Maksimovic, “Three-level buck converter for envelope tracking applications", in IEEE Transactions on Power Electronics, vol. 21, no. 2, pp. 549-552, March 2006.

[43] M. C. W. Hoyerby and M. E. Andersen, "High-Bandwidth, HighEfficiency Envelope Tracking Power Supply for 40W RF Power Amplifier Using Paralleled Bandpass Current Sources”, in IEEE Power Electronics Specialists Conference, Recife, 2005, pp. 2804-2809.

[44] M. Rodríguez, P. F. Miaja, A. Rodríguez and J. Sebastián, “A Multiple-Input Digitally Controlled Buck Converter for Envelope Tracking Applications in Radiofrequency Power Amplifiers”, in IEEE Transactions on Power Electronics, vol. 25, no. 2, pp. 369381, Feb. 2010.

[45] M. Rodríguez, P. F. Miaja, A. Rodríguez and J. Sebastián, "Multilevel converter for Envelope Tracking in RF power amplifiers", in IEEE Energy Conversion Congress and Exposition, San José, 2009, pp. 503-510.

[46] J. Sebastián, P. Fernández-Miaja, A. Rodríguez, and M. Rodríguez, "Analysis and design of the output filter for buck envelope amplifiers,” IEEE Transactions on Power Electronics, vol. 29, no. 1, pp. 213-233, Jan. 2014.

[47] J. Sebastián, P. F. Miaja, F. J. Ortega-González, M. Patiño and M. Rodríguez, "Design of a Two-Phase Buck Converter With Fourth-Order Output Filter for Envelope Amplifiers of Limited Bandwidth”, in IEEE Transactions on Power Electronics, vol. 29, no. 11, pp. 5933-5948, Nov. 2014.

[48] Y. Zhang, M. Rodríguez and D. Maksimović, "100 MHz, $20 \mathrm{~V}$, $90 \%$ efficient synchronous buck converter with integrated gate 
driver”, in IEEE Energy Conversion Congress and Exposition, Pittsburgh, 2014, pp. 3664-3671.

[49] P. F. Miaja, A. Rodríguez and J. Sebastián, "Buck-Derived Converters Based on Gallium Nitride Devices for Envelope Tracking Applications", in IEEE Transactions on Power Electronics, vol. 30, no. 4, pp. 2084-2095, April 2015.

[50] O. García, M. Vasic, P. Alou, J. A. Oliver and J. A. Cobos, "An overview of fast DC-DC converters for envelope amplifier in RF transmitters", IEEE Applied Power Electronics Conference and Exposition, Orlando, 2012, pp. 1313-1318.

[51] F. Wang et al., "An Improved Power-Added Efficiency 19-dBm Hybrid Envelope Elimination and Restoration Power Amplifier for 802.11g WLAN Applications," in IEEE Transactions on Microwave Theory and Techniques, vol. 54, no. 12, pp. 40864099, Dec. 2006.

[52] M. Vasic, O. García, J. A. Oliver, P. Alou, D. Díaz and J. A. Cobos, "Multilevel Power Supply for High-Efficiency RF Amplifiers," in IEEE Transactions on Power Electronics, vol. 25, no. 4, pp. 1078-1089, April 2010.

[53] V. Yousefzadeh, E. Alarcón and D. Maksimovic, "Band Separation and Efficiency Optimization in Linear-Assisted Switching Power Amplifiers," IEEE Power Electronics Specialists Conference, Jeju, 2006, pp. 2761-2767.

[54] P. F. Miaja, J. Sebastián, R. Marante and J. A. García, "A Linear Assisted Switching Envelope Amplifier for a UHF Polar Transmitter," in IEEE Transactions on Power Electronics, vol. 29, no. 4, pp. 1850-1861, April 2014.

[55] M. Vasić, O. García, J. A. Oliver, P. Alou and J. A. Cobos, "Theoretical Efficiency Limits of a Serial and Parallel LinearAssisted Switching Converter as an Envelope Amplifier," in IEEE Transactions on Power Electronics, vol. 29, no. 2, pp. 719728, Feb. 2014.

[56] J. Rodríguez, P. F. Miaja, D. G. Lamar and J. Sebastián, “Taking Advantage of the Output Voltage Ripple of a Two-Phase Buck Converter to Perform Quadrature Amplitude Modulation for Visible Light Communication”, IEEE Applied Power Electronics Conference and Exposition, Tampa, 2017, pp. 2116-2123.

[57] J. Rodríguez, D. García-Aller, D. González-Lamar and J. Sebastián, "Energy efficient Visible Light Communication transmitter based on the split of the power", IEEE Energy Conversion Congress and Exposition, Cincinnati, 2017, pp. 217224.

[58] J. Rodríguez, D. García-Aller, D. González-Lamar and J. Sebastián, "Performance evaluation of a VLC transmitter based on the split of the power", IEEE Applied Power Electronics Conference and Exposition, San Antonio, 2018.

[59] J. Rodríguez, P. F. Miaja, D. González-Lamar and J. Sebastián, "Reproducing single-carrier digital modulation schemes for VLC by controlling the first switching harmonic of the DC-DC power converter output voltage ripple". Accepted for publication in IEEE Transactions on Power Electronics. DOI: 10.1109/TPEL.2017.2774178.

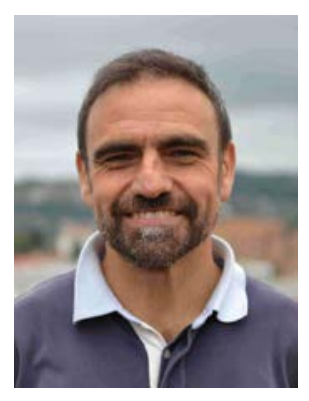

Javier Sebastián (M’87-SM’11) was born in Madrid, Spain, in 1958. He received the M.Sc. degree from the Technical University of Madrid (UPM), and the Ph.D. degree from the University of Oviedo, Spain, in 1981 and 1985, respectively. He was an Assistant Professor and an Associate Professor at both the UPM and the University of Oviedo. Since 1992, he has been with the University of Oviedo, where he is currently a Professor. His research interests are switching-mode power supplies, modeling of dc-to-dc converters, low output voltage dcto-dc converters, high power factor rectifiers, LED drivers, dc-todc converters for envelope tracking techniques and the use of wide band-gap semiconductors in power supplies.

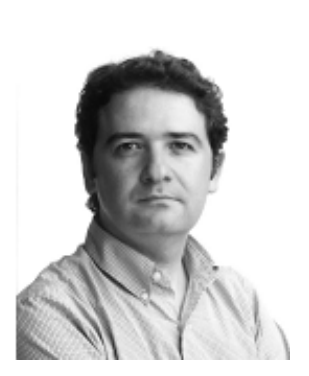

Diego G. Lamar (M’08) was born in Zaragoza, Spain, in 1974. He received the M.Sc. degree, and the Ph.D. degree in Electrical Engineering from the University of Oviedo, Spain, in 2003 and 2008, respectively. In 2003 and 2005 he became a Research Engineer and an Assistant Professor respectively at the University of Oviedo. Since September 2011, he has been an Associate Professor. His research interests are focused on switching-mode power supplies, converter modelling, and power-factor-correction converters.

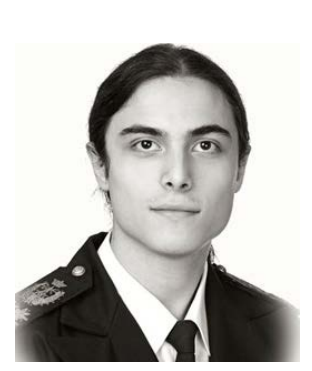

Daniel G. Aller (S'16) was born in Oviedo, Spain, in 1992. He received the M. Sc. degree in Telecommunication engineering in 2016 from the University of Oviedo, Gijon, Spain, where he is currently working towards the Ph.D degree in electrical engineering. His research interests include LED drivers for visible light communication, highfrequency DC-DC converters and wide bandgap semiconductors.

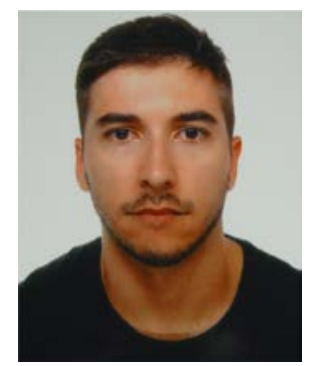

Juan Rodríguez (S’15) was born in Avilés, Spain, in 1991. He received the M.Sc. degree in telecommunication engineering from the University of Oviedo, Spain, in 2014, where he is currently working towards the Ph.D. degree in electrical engineering. His research interests are focused on highfrequency DC-DC power converters, wide bandgap semiconductors and LED drivers for visible light communication. 


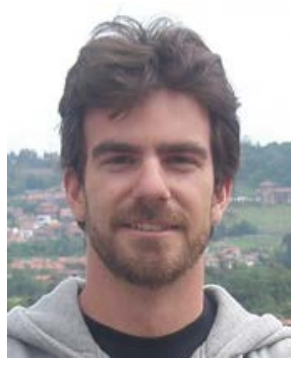

Pablo F. Miaja (S'07 M'13) was born in Oviedo, Spain, in 1984. He received the M.S. degree in telecommunication engineering from the University of Oviedo (Spain) in 2007 and in 2012 the $\mathrm{PhD}$. degree from the same university. Between December 2007 and November 2014 he worked as a researcher at the Electronic Power Supply Systems Group of the University of Oviedo (Spain).

Between November 2014 and May 2016 he was a Research Associate at the Power conversion Group of the University of Manchester (UK). Since June 2016 he is an Electrical Power Conditioning Engineer at the Electrical Power Management Section at the European Space Agency. His research interests include dc/dc conversion, digital control of switched converters and power-supply systems for communication equipment. 